This document is confidential and is proprietary to the American Chemical Society and its authors. Do not copy or disclose without written permission. If you have received this item in error, notify the sender and delete all copies.

\title{
Tuning the thermal properties and morphology of isodimorphic poly[(butylene succinate)-ran- $(\varepsilon-$ caprolactone)] copolyesters by changing composition, molecular weight and thermal history
}

\begin{tabular}{|r|l|}
\hline Journal: & Macromolecules \\
\hline Manuscript ID & ma-2018-017424.R2 \\
\hline Manuscript Type: & Article \\
\hline Author: & 09-Nov-2018 \\
\hline Complete List of Authors: & $\begin{array}{l}\text { Safari, Maryam; Universidad del Pais Vasco, Chemistry } \\
\text { Martínez de Ilarduya, Antxon; UPC, Chem. Eng } \\
\text { Mugica, Agurtzane; Facultad de Químicas (UPV/EHU), ciencia y } \\
\text { tecnologia de polimeros } \\
\text { Zubitur, Manuela; Escuela Universitaria Politecnica, (UPV/EHU), } \\
\text { ingenieria quimica y del medio ambiente } \\
\text { Muñoz-Guerra, Sebastián; UPC, Chemical Engineering } \\
\text { Müller, Alejandro; Faculty of Chemistry,University of the Basque Country } \\
\text { (UPV/EHU), Polymer Science and Technology Department }\end{array}$ \\
\hline
\end{tabular}

\section{SCHOLARONE $^{\text {m }}$ Manuscripts}




\title{
Tuning the thermal properties and morphology of isodimorphic poly/(butylene succinate)-ran-(E-caprolactone)] copolyesters by changing composition, molecular weight and thermal history
}

\author{
Maryam Safari ${ }^{1}$, Antxon Martínez de Ilarduya ${ }^{2}$, Agurtzane Mugica $^{1}$, Manuela Zubitur ${ }^{3}$, \\ Sebastián Muñoz-Guerra², Alejandro J. Müller*1,4 \\ ${ }^{1}$ POLYMAT and Polymer Science and Technology Department, Faculty of Chemistry, \\ University of the Basque Country UPV/EHU, Paseo Manuel de Lardizabal, 3, 20018 \\ Donostia-San Sebastián, Spain \\ ${ }^{2}$ Departament d'Enginyeria Química, Universitat Politècnica de Catalunya, \\ ETSEIB, Diagonal 647, 08028 Barcelona, Spain \\ ${ }^{3}$ Chemical and Environmental Engineering Department, Polytechnic School, University of \\ the Basque Country (UPV/EHU), 2008 Donostia-San Sebastián, Spain \\ ${ }^{4} I K E R B A S Q U E$, Basque Foundation for Science, Bilbao, Spain
}

*Corresponding author: alejandrojesus.muller@ehu.es 


\section{Abstract}

High molecular weight poly[(butylene succinate)-ran-( $\varepsilon$-caprolactone)] copolyesters (PBS-ran-PCL) were synthesized in a wide composition range and compared with significantly lower molecular weight samples synthesized previously. DSC and WAXS showed that these copolyesters are isodimorphic (i.e., each crystalline phase contains a small amount of the second comonomer) as they able to crystallize in the entire composition range, display a pseudoeutectic point, and their unit cell dimensions are a function of composition. Copolymers close or away from the pseudo-eutectic point exhibited a single crystalline phase, i.e., PBS-rich or PCL-rich crystalline phase. At the pseudo-eutectic point, both phases are able to crystallize in double crystalline banded spherulites, as demonstrated by Polarized Light Optical Microscopy (PLOM) studies. An increase in molecular weight of the copolyester does not influence $T_{m}$ and $T_{\mathrm{c}}$ significantly, as their values are determined by the randomness of the comonomer distribution. However, crystallinity values are higher for lower $M_{w}$ copolymers because of their faster crystallization rate. Copolymers with higher $M_{w}$ exhibited higher $T_{g}$ values as expected for random copolymers that are characterized by a single phase in the amorphous regions. Therefore, changing composition and molecular weight, a remarkable separate control over $T_{g}$ and $T_{m}$ values can be achieved in these copolyesters. SAXS results revealed that the lamellar thickness $l_{c}$ decreases with composition at each side of the eutectic point. Comonomer exclusion limits the length of crystallizable sequences; as a result, the lamellar thickness values do not significantly vary with $M_{w}$ in the range studied here. At the pseudo-eutectic copolyester compositions, the cooling rate determines for both series of samples (low and high $M_{w}$ ) if one or two crystalline phases can develop: only PCL-rich crystalline phase, only PBS-crystalline phase or both crystalline phases. This behavior was studied in detail by DSC, in situ WAXS/SAXS and PLOM. Our studies demonstrate that these biodegradable copolymers are versatile materials, whose properties can be tuned by composition, molecular weight and thermal history to better target specific applications.

Keywords: Poly(E-caprolactone), Poly(butylene succinate), random copolyesters, molecular weight, isodimorphism, cooling rate dependence. 


\section{Introduction}

Crystallizable random copolymers display a wide variety of properties depending on the chemical structure of the two comonomeric units and their composition. Considering two potentially crystallizable components, three different cases are possible, which have been recently reviewed. ${ }^{1}$

The first case is that of total comonomer inclusion inside the crystal unit cell, or cocrystallization in the entire composition range. A plot of melting temperature versus composition yields a straight line that follows a simple rule of mixtures. These copolymers are denoted as isomorphic. ${ }^{2,3}$ In the case of copolyesters, very few cases of isomorphism have been reported, ${ }^{4-7}$ and they occur when the chemical structure of both comonomers are very similar.

The second case occurs when the chemical structure of the two constituent comonomers differ more than in the previous case. A competition between exclusion and inclusion (inside the crystal lattice) of the minor comonomer component with respect to the major comonomer component is established during crystallization. But in these copolymers, there is always a small amount of inclusion of the second comonomer within the crystal unit cell of the majority comonomer. As a result, the copolymers crystallize in the entire composition range and are classified as isodimorphic. This means that two crystalline phases are formed with crystal structures that resemble those of the parent homopolymers. When the melting temperature is plotted as a function of composition, a pseudo-eutectic point is observed. To each side of the eutectic, only one crystalline phase is formed, that is rich in the major component with limited inclusion of the second comonomer. We have recently found that at the eutectic point, two crystalline phases can co-exist depending on the thermal history, with crystalline unit cells 
resembling those of the parent homopolymers. ${ }^{1}$ Several isodimorphic random copolyesters have been recently studied. ${ }^{8-18}$

The third and final case is that of total exclusion of the minor comonomeric units and it is the most frequently reported case, when the chemical structures of the comonomers are very different from one another. For random copolyesters, this behavior has been reported by Soccio et al. in poly(propylene isophthalate-ran-propylene succinate) ${ }^{19}$ and poly(propylene isophthalate-ran-propylene adipate). ${ }^{20}$

Aliphatic biodegradable polyesters, such as poly (butylene succinate) (PBS) and poly ( $\varepsilon$-caprolactone) (PCL) have received much attention since they are potentially biodegradable and may contribute to reduce environmental pollution caused by plastic waste. ${ }^{21,} 22$ The combination of PCL and PBS as random or block copolyesters, has been used to design new materials with improved behavior and performance. ${ }^{23,}{ }^{24}$ The mechanical and functional properties of semicrystalline polymers depend on structural and morphological features that are controlled by their molecular weight and crystallization conditions during processing. ${ }^{25,26}$ To enhance product performance of random copolyesters for specific applications, it is essential to know in detail how the molecular weight and composition influence their main properties.

Recently, we synthesized poly[(butylene succinate)-ran-( -caprolactone)] s (PBS-ranPCL) by enzymatic ring opening polymerization. The copolyesters obtained had low molecular weights (in most cases the weight average molecular weight was lower than $6000 \mathrm{~g} / \mathrm{mol}$ ), but they displayed a remarkable isodimorphic behavior. ${ }^{27}$ In this work, higher molecular weight poly (butylene succinate-ran-caprolactone)s (PBS-ran-PCL) copolyesters were prepared in a wide composition range by changing the synthetic strategy to a direct transesterification/ROP and polycondensation route. A detailed comparison between the results obtained with the 
presently synthesized high molecular weight copolyesters (denoted $\mathrm{HM}_{\mathrm{w}} \mathrm{BS}_{\mathrm{x}} \mathrm{CL}_{\mathrm{y}}$, where $\mathrm{x}$ and $\mathrm{y}$ are the molar \% of BS and CL units respectively) and our previous series of copolyesters with lower molecular weight (denoted $\mathrm{LM}_{\mathrm{w}} \mathrm{BS}_{\mathrm{x}} \mathrm{CL}_{\mathrm{y}}$ ) ${ }^{27}$ is presented.

Cao et al. ${ }^{28}$ also prepared PBS-ran-PCL copolymers with a similar synthetic approach. However, to the best of our knowledge, this is the first time that the non-isothermal crystallization and thermal transitions of these copolymers have been studied as a function of molecular weight. In the current investigation, non-isothermal crystallization of $\mathrm{HM}_{\mathrm{w}} \mathrm{BS}_{\mathrm{x}} \mathrm{CL}_{\mathrm{y}}$ and their parent homopolymers are studied by means of polarized light optical microscopy (PLOM), differential scanning calorimetry (DSC), in situ simultaneous synchrotron wide angle X-ray scattering (WAXS) and small angle X-ray scattering (SAXS). We investigate the role of molecular weight and composition on the thermal properties, structure and crystallization of these random copolyesters. Additionally, we have found remarkable results at the pseudoeutectic composition by varying the cooling rate from the melt, so that the formation of one or two crystalline phases can be controlled.

\title{
2. Experimental
}

Materials

\author{
Dimethyl succinate (DMS), 1,4-butanediol (BD), titanium tetraisopropoxide (TTP) \\ catalyst, and $\varepsilon$-caprolactone (CL) were purchased from Aldrich company. All materials were \\ used as received.
}




\section{Synthesis of $\mathrm{HM}_{\mathrm{w}} \mathrm{BS}_{\mathrm{x}} \mathrm{CL}$}

Concisely, for the $\mathrm{BS}_{51} \mathrm{CL}_{49}$ a three-necked $50 \mathrm{ml}$ flask was charged with $1.46 \mathrm{~g}$ (10 mmol) of dimethyl succinate (DMS), $1.38 \mathrm{~g}$ (15 mmol) of 1,4-butanediol (BD), and 1.140g (10 mmol) of $\varepsilon$-caprolactone. DMS /CL mixtures at molar ratios of 90/10, 80/20,70/30, 60/40, $55 / 45,50 / 50,45 / 55,40 / 60,30 / 70,20 / 80$ and 10/90, were used so the whole range of compositions was essentially covered.

DMS BD
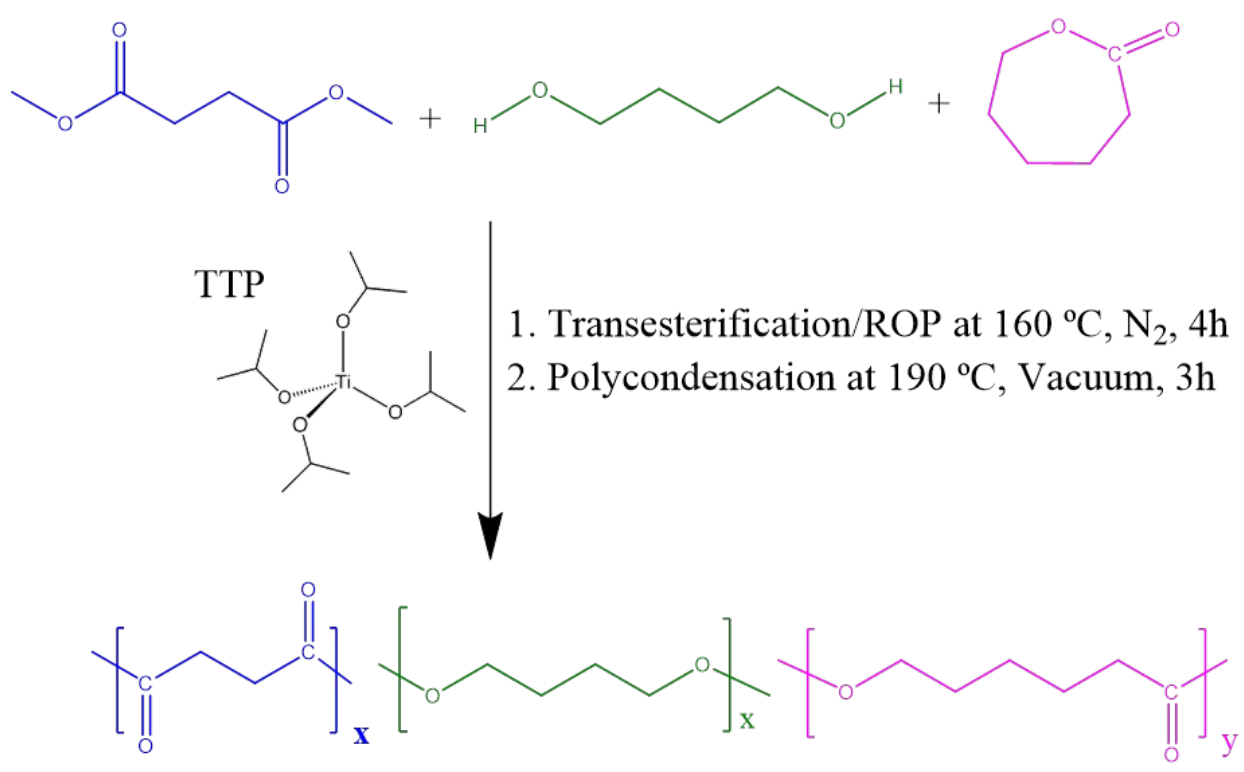

Scheme 1. Synthetic route for the preparation of $\mathrm{HM}_{w} \mathrm{BS}_{\mathrm{x}} \mathrm{CL}_{\mathrm{y}}$.

The mixture was left under mechanical stirring in a thermostatized silicon oil bath until the temperature stabilized at $160{ }^{\circ} \mathrm{C}$ and the medium became homogeneous. Then $0.16 \mu 1$ $(0.0005 \mathrm{mmol})$ of TTP with the TTP $/ \varepsilon$-CL molar ratio equal to $0.005 \%$ were added under gentle agitation at $50 \mathrm{rpm}$. The transesterification/ROP reaction was conducted for $4 \mathrm{~h}$ and finally the polycondensation was performed under gradually reduced pressure to a final value of $0.1 \mathrm{~mm}$ 
$\mathrm{Hg}$ at $190^{\circ} \mathrm{C}$ for around $3 \mathrm{~h}$. The high molecular weight values are possibly due to the high vacuum applied during the polycondensation step. The same process was carried out for the synthesis of the corresponding homopolyesters PBS and PCL using DMS and $\varepsilon$-CL as respective feeds. Scheme 1 shows the route leading to $\mathrm{HM}_{\mathrm{w}} \mathrm{BS}_{\mathrm{x}} \mathrm{CL}_{\mathrm{y}}$ copolyesters using TTP catalyst.

Table 1. Synthesis results of the copolymerization of butylene succinate and $\varepsilon$-caprolactone.

\begin{tabular}{|c|c|c|c|c|c|c|c|c|c|}
\hline \multirow[t]{2}{*}{ Polyester } & \multicolumn{2}{|c|}{$\begin{array}{c}\text { Composition }{ }^{\mathrm{a}} \\
(\mathrm{BS} / \mathrm{CL} \mathrm{mol} / \mathrm{mol}) \\
\end{array}$} & \multicolumn{3}{|c|}{$\begin{array}{l}\text { Molecular weight }{ }^{\mathrm{b}} \\
(\mathrm{g} / \mathrm{mol})\end{array}$} & \multicolumn{4}{|c|}{$\begin{array}{c}\text { Microstructure }^{\mathrm{c}} \\
\text { (S-centered triads content) }\end{array}$} \\
\hline & Feed & Found & $M_{\mathrm{n}}$ & $M_{\mathrm{w}}$ & $Ð$ & BSB & BSCL/CLSB & CLSCL & $R$ \\
\hline PBS & $100 / 0$ & $100 / 0$ & 7500 & 21470 & 2.9 & - & - & - & - \\
\hline $\mathrm{BS}_{91} \mathrm{CL}_{9}$ & $90 / 10$ & $91 / 09$ & 8790 & 21640 & 2.5 & 1 & 21 & 78 & 1.08 \\
\hline $\mathrm{BS}_{78} \mathrm{CL}_{22}$ & $80 / 20$ & $78 / 22$ & 6580 & 18000 & 2.7 & 4 & 23 & 73 & 1.03 \\
\hline $\mathrm{BS}_{66} \mathrm{CL}_{34}$ & $70 / 30$ & $66 / 34$ & 7830 & 19700 & 2.5 & 9 & 37 & 54 & 1.05 \\
\hline $\mathrm{BS}_{62} \mathrm{CL}_{38}$ & $60 / 40$ & $62 / 38$ & 9750 & 27300 & 2.8 & 9 & 38 & 53 & 1.05 \\
\hline $\mathrm{BS}_{55} \mathrm{CL}_{45}$ & $55 / 45$ & $55 / 45$ & 8970 & 24700 & 2.7 & 10 & 39 & 51 & 0.98 \\
\hline $\mathrm{BS}_{51} \mathrm{CL}_{49}$ & $50 / 50$ & $51 / 49$ & 7400 & 23500 & 3.1 & 17 & 45 & 41 & 1.00 \\
\hline $\mathrm{BS}_{45} \mathrm{CL}_{55}$ & $45 / 55$ & $45 / 55$ & 8000 & 17300 & 2.2 & 20 & 43 & 37 & 1.03 \\
\hline $\mathrm{BS}_{38} \mathrm{CL}_{62}$ & $40 / 60$ & $38 / 62$ & 11000 & 24300 & 2.2 & 25 & 47 & 28 & 1.05 \\
\hline $\mathrm{BS}_{34} \mathrm{CL}_{66}$ & $30 / 70$ & $34 / 66$ & 10000 & 29900 & 2.2 & 27 & 50 & 23 & 1.08 \\
\hline $\mathrm{BS}_{27} \mathrm{CL}_{73}$ & $20 / 80$ & $27 / 73$ & 11540 & 28700 & 2.5 & 31 & 48 & 21 & 1.05 \\
\hline $\mathrm{BS}_{11} \mathrm{CL}_{89}$ & $10 / 90$ & $11 / 89$ & 6300 & 19500 & 3.1 & 55 & 40 & 5 & 0.98 \\
\hline PCL & $0 / 100$ & $0 / 100$ & 5400 & 17400 & 3.2 & - & - & - & - \\
\hline
\end{tabular}

${ }^{a}$ Composition of the feed and the resulting polymer as determined by ${ }^{1} \mathrm{H} N M R$.

${ }^{\mathrm{b}}$ Number and weight average molecular weights and dispersities estimated by GPC against PMMA standards.

${ }^{\mathrm{c}}$ Copolyester microstructure determined by NMR; $R$ is the degree of randomness which should be 1 for a fully statistical distribution of the comonomeric units. 
Table 1 shows molecular weight and microstructural data for the synthesized copolyesters in the presence of TTP catalyst. The microstructure of the prepared copolyesters is essentially random as judged by the triads contents and $\mathrm{R}$ values given in Table 1 . NMR results confirm the chemical structure of copolyesters. ${ }^{1} \mathrm{H}$ and ${ }^{13} \mathrm{C}$ NMR spectra, of the $\mathrm{BS}_{51} \mathrm{CL}_{49}$ copolyester are shown in Figure SI-1 (see Supporting Information), and the spectra of the entire series are compared in Figure SI-2.

The weight average molecular weights $\left(M_{w}\right)$ of the $\mathrm{HM}_{\mathrm{w}} \mathrm{BS}_{\mathrm{x}} \mathrm{CL}_{\mathrm{y}}$ copolyesters are in the range $17000-30000 \mathrm{~g} / \mathrm{mol}$ with dispersities $(Ð)$ between 2.2 and 3.2. Overall, the $M_{w}$ of $\mathrm{HM}_{\mathrm{w}}$ $\mathrm{BS}_{\mathrm{x}} \mathrm{CL}_{\mathrm{y}}$ copolyesters are approximately four times higher than most of the similar copolyesters previously synthesized by enzymatic (CALB) ROP copolymerization $\left(\mathrm{LM}_{\mathrm{w}} \mathrm{BS}_{\mathrm{x}} \mathrm{CL}_{\mathrm{y}}\right)$ in our previous work (see Table SI-1). ${ }^{27}$

\section{Nuclear Magnetic Resonance (NMR)}

The ${ }^{1} \mathrm{H}$ NMR and ${ }^{13} \mathrm{C}$ NMR spectra were operated at 300.1 and $75.5 \mathrm{MHz}$ respectively, on a Bruker AMX-300 NMR instrument. The samples were dissolved in deuterated chloroform and TMS was used as internal reference. Quantitative ${ }^{13} \mathrm{C}$ NMR spectra were recorded applying an inverse gated decoupling pulse sequence to avoid nuclear Overhauser effect (NOE) enhancement of the ${ }^{13} \mathrm{C}$ NMR signals, and using long delay times. The composition of $\varepsilon$ caprolactone repeating unit present in $\mathrm{BS}_{\mathrm{x}} \mathrm{CL}_{\mathrm{y}}$ was estimated from methylene proton resonance integrals of $\mathrm{CH}_{2}(1)$ and $\mathrm{CH}_{2}$ (4). Moreover, the sequence distributions of BS and CL repeating units were calculated based on ${ }^{13} \mathrm{C}$ NMR signals of the methylene group $\mathrm{CH}_{2}$ (b) in Figure SI1. 


\section{Gel Permeation Chromatography (GPC)}

Molecular weight properties were measured by Gel Permeation Chromatograms (GPC) that were acquired at $35{ }^{\circ} \mathrm{C}$ with a Waters equipment, a refraction index detector and poly (methyl methacrylate) (PMMA) standards. The samples were chromatographed with $0.05 \mathrm{M}$ sodium trifluoroacetate-hexafluoroisopropanol (NaTFA-HFIP) using a poly(styrene-co-divinyl benzene) packed linear column at a flow rate of $0.5 \mathrm{ml} / \mathrm{min}$.

\section{Thermal behavior}

Differential Scanning Calorimetry (DSC) experiments were performed using a Perkin Elmer 8500 calorimeter equipped with a refrigerated cooling system Intracooler 2P, under a nitrogen atmosphere flow of $20 \mathrm{ml} / \mathrm{min}$ and calibrated with high purity indium and tin standards. Samples crystallization experiments were hermetically sealed in standard aluminum pans and tested according to the following protocol: Samples were heated from room temperature to 30 ${ }^{\circ} \mathrm{C}$ above their melting temperature $\left(T_{m}\right)$ and held at this temperature for 3 min to erase thermal history. They were then cooled to $-60^{\circ} \mathrm{C}$ and reheated again to $30{ }^{\circ} \mathrm{C}$ above their $T_{m}$. Measurements were done at two different scan rates, $20^{\circ} \mathrm{C} / \mathrm{min}$ and $10^{\circ} \mathrm{C} / \mathrm{min}$, with the purpose of evaluating the scan rate effect on melting and crystallization behavior. The melting temperature $T_{m}$ was determined from the second scan as the temperature of the main peak in the DSC curves.

To determine the glass transition temperature $\left(T_{g}\right)$, samples were heated from room temperature to $140{ }^{\circ} \mathrm{C}$ (for BS-rich samples) or $90{ }^{\circ} \mathrm{C}$ (for CL-rich samples) at a rate of 10 ${ }^{\circ} \mathrm{C} / \mathrm{min}$. They were then cooled using the ballistic cooling option of DSC 8500, which cools the sample at an average nominal rate of approximately $160^{\circ} \mathrm{C} / \mathrm{min}$ ) to $-90^{\circ} \mathrm{C}$. Finally, the sample was heated to $140{ }^{\circ} \mathrm{C}$ (for BS-rich samples) or $90{ }^{\circ} \mathrm{C}$ (for CL-rich samples) at a rate of 20 
${ }^{\circ} \mathrm{C} / \mathrm{min}$. The glass transition temperatures, $T_{g}$, were calculated from the DCS scans as the midpoint of the heat capacity change.

\section{X-ray diffraction}

The samples were examined under non-isothermal conditions by simultaneous in situ WAXS/SAXS performed at beamline BL11-NCD at the ALBA Synchrotron radiation facility, in Barcelona, Spain. The samples in DSC pans were placed in a Linkam THMS600 stage coupled to a liquid nitrogen cooling system. Firstly, they were heated at $10^{\circ} \mathrm{C} / \mathrm{min}$ from room temperature to $30^{\circ} \mathrm{C}$ above the melting temperature $T_{m}$ and held for $3 \mathrm{~min}$ to erase their thermal history. Secondly, the samples were cooled down to $-60{ }^{\circ} \mathrm{C}$ at a rate of $10{ }^{\circ} \mathrm{C} / \mathrm{min}$ and held at this temperature for $5 \mathrm{~min}$. Thirdly, the samples were heated up to $30^{\circ} \mathrm{C}$ above the melting point at $10^{\circ} \mathrm{C} / \mathrm{min}$ rate. During the mentioned protocol, SAXS/WAXS spectra were recorded every 10 seconds.

WAXS and SAXS scans were taken periodically at two scans per degree centigrade. The energy of the X-ray source was $12.4 \mathrm{keV}(\lambda=1.0 \AA)$. In the WAXS configuration, the sample-detector (WAXS detector, Rayonix LX255-HS with an active area of $230.4 \times 76.8 \mathrm{~mm}$ (pixel size: $44 \mu \mathrm{m}^{2}$ )) distance employed was $15.5 \mathrm{~mm}$ with a tilt angle of $27.3^{\circ}$. In the case of the SAXS configuration, the sample-detector (SAXS detector, Pilatus 1M (from Dectris)) had an activated image area of $168.7 \times 179.4 \mathrm{~mm}^{2}$, a total number of pixels of $981 \times 1043,172 \times 172$ $\mu \mathrm{m}^{2}$ pixels size, frame rate of 25 frames $/ \mathrm{sec}$, and the distance employed was $6463 \mathrm{~mm}$. The intensity profile was output as the plot of the scattering intensity vs scattering vector, $q=4 \pi \sin \theta \lambda^{-}$

1 , where $\lambda$ is the $\mathrm{X}$-ray wavelength $(\lambda=1 \AA)$ and $2 \theta$ is the scattering angle. The scattering vector was calibrated using silver behenate (SAXS) and chromium (III) oxide (WAXS). 


\section{Polarized Light Optical Microscopy (PLOM)}

A polarized light optical microscope, Olympus BX51 equipped with an Olympus SC50 digital camera and in combination with a Linkam TP-91 hot stage was used to observe spherulite development. Films with around $10 \mu \mathrm{m}$ thickness were prepared by melting the samples in between two glass slides. For non-isothermal experiments, the samples were first heated to 30 ${ }^{\circ} \mathrm{C}$ above their melting point $T_{m}$ to erase their thermal history and then they were crystallized from the melt by cooling to $20^{\circ} \mathrm{C}$ below their crystallization temperature $T_{c}$ at $10{ }^{\circ} \mathrm{C} / \mathrm{min}$.

\section{Results and Discussion}

The thermal behavior of the samples was explored by non-isothermal DSC experiments. The samples were first heated to a temperature high enough to erase their thermal history, and then they were cooled at $10^{\circ} \mathrm{C} / \mathrm{min}$. After this controlled cooling, their melting behavior was recorded in the DSC second heating scans shown in Figure 1a. The previous cooling runs as well as the calorimetric data derived from all the DSC non-isothermal runs can be found in the Supplementary Information (see Figure SI-3 and Tables SI-2 and SI-3).

Figure 1a shows that these random copolymers are able to crystallize in the entire composition range, even for compositions close to equimolarity. As demonstrated by NMR, the copolymers are random (see Table 1 , values of $\mathrm{R}=1$ indicate complete randomness). Only isomorphic or isodimorphic random copolymers can crystallize in the entire composition range. However, Figure 1b illustrates that the melting point follows a pseudo-eutectic trend with composition indicating that the $\mathrm{HM}_{\mathrm{w}}$ PBS-ran-PCL copolymers are isodimorphic. ${ }^{1,3}$ In the $\mathrm{HM}_{\mathrm{w}} \mathrm{BS}_{45} \mathrm{CL}_{55}$ sample, there are two melting temperatures and two crystallization temperatures 
indicating the presence of two crystalline phases at the eutectic point, i.e., a PCL-rich and a PBS-rich crystalline phases.

Figure $1 \mathrm{~b}$ also illustrates the tremendous versatility of these random copolyesters. Thanks to their isodimorphic character, their melting point can be tailored by changing composition with a variation of $100{ }^{\circ} \mathrm{C}$.

In isodimorphic copolymers, the comonomer that constitutes the major phase typically crystallizes with the unit cell of its corresponding homopolymer, but including a small number of comonomer units of the minor second component within the crystal lattice. There is always a competition between comonomer exclusion and comonomer inclusion in isodimorphic copolymers. Their behavior is typically dominated by a higher amount of comonomer exclusion but comonomer inclusion is indispensable for crystallization in the entire composition range.

According to WAXS results (see Figure 1c), to the left side of the pseudo-eutectic point, only PBS-like crystals are formed and to the right side of this point, only PCL-like crystals are found. The indexation of the WAXS patterns can be found in the Supporting Information along with WAXS data taken at different temperatures (see Figures SI-7 and Table SI-4 and Table SI5). In $\mathrm{HM}_{\mathrm{w}} \mathrm{BS}_{\mathrm{x}} \mathrm{CL}_{\mathrm{y}}$ copolymers, for the composition that corresponds to the eutectic point ( $\mathrm{BS}_{45} \mathrm{CL}_{55}$ ), two crystalline phases (PBS-rich crystalline phase and PCL-rich crystalline phase) were found that correspond to those observed by DSC (See figure SI-3 and table SI-2). 
(a)

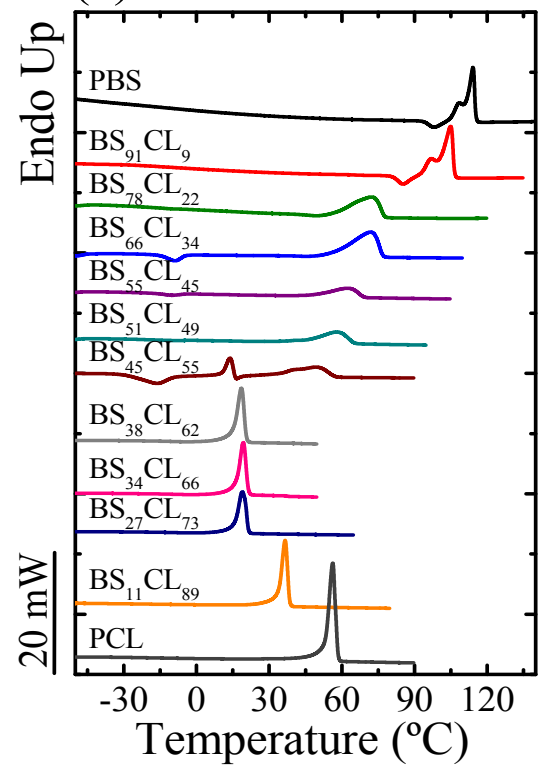

(c)

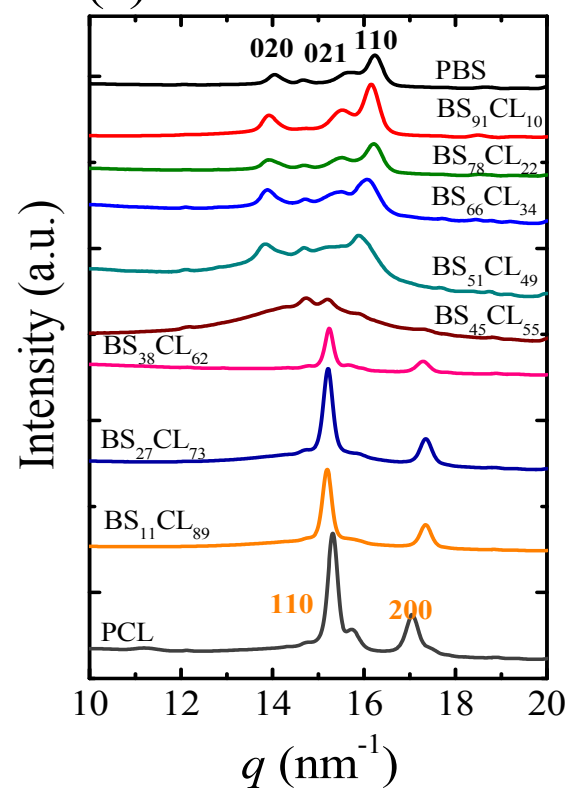

(b)

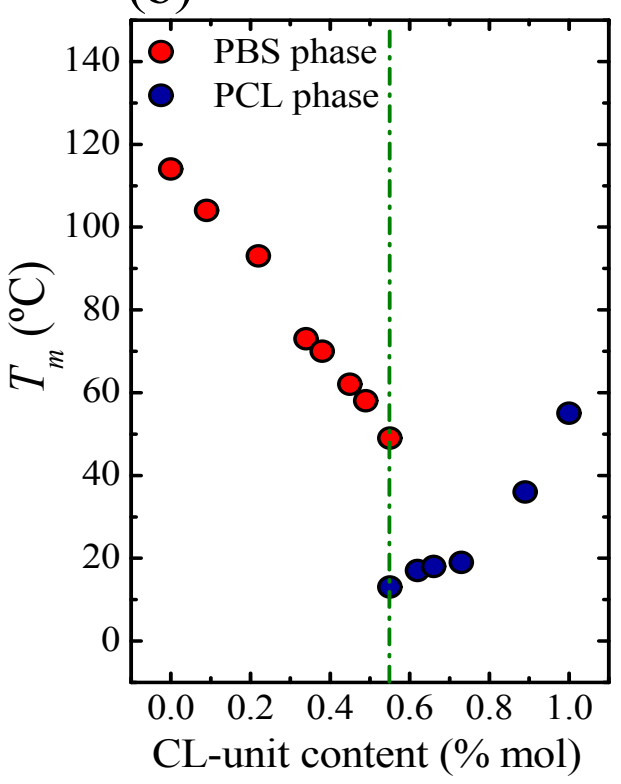

(d)

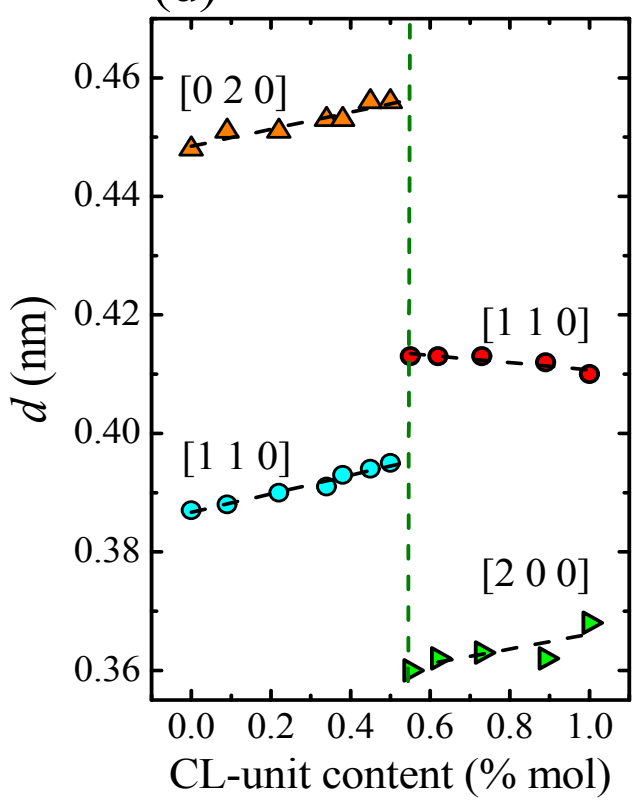

Figure 1. (a) DSC second heating runs at $10{ }^{\circ} \mathrm{C} / \mathrm{min}$ for the indicated $\mathrm{HM}_{\mathrm{w}}$ samples. (b) Peak melting temperature as a function of composition, the dashed vertical line indicates the pseudoeutectic composition. (c) WAXS diffraction patterns taken at $-60^{\circ} \mathrm{C}$ after cooling from the melt at $10^{\circ} \mathrm{C} / \mathrm{min}$. (d) $d$-spacings obtained from the WAXS results presented in (c) as a function of composition. 
The $d$-spacings observed in the WAXS profiles registered at $-60^{\circ} \mathrm{C}$ versus $\mathrm{CL}$ unit content are plotted in Figure $1 \mathrm{~d}$. At $-60^{\circ} \mathrm{C}, d$-spacings for PBS-rich crystalline phases arising from (020) and (110) planes, as well as those for PCL-rich crystalline phases corresponding to (110) planes, display an increasing trend with comonomer content. These increases correspond to changes in unit cell sizes that reflect a certain degree of comonomer inclusion that takes place within the crystal unit cells of the corresponding crystal phases of these random copolymers. The $d$-spacings observed in the WAXS profiles registered versus CL-unit content at $-60{ }^{\circ} \mathrm{C}$ and $25^{\circ} \mathrm{C}$ are compared in Figure SI-8.

The results presented in Figure 1 are fully consistent with the isodimorphic character of the $\mathrm{HM}_{\mathrm{w}}$ PBS-ran-PCL copolymers. These results are qualitatively similar to those obtained previously by us with $\mathrm{LM}_{\mathrm{w}}$ PCL-ran-PBS copolymers. ${ }^{27}$ The specific differences observed between low and high $M_{w}$ copolymers are discussed in the next section.

We studied the effect of copolymer composition on the spherulitic texture of $\mathrm{HM}_{\mathrm{w}}$ PCLran-PBS copolyesters. Figure SI-5 shows PLOM micrographs during non-isothermal crystallization, after spherulites had impinged on each other for $\mathrm{HM}_{\mathrm{w}}$ copolymers. The incorporation of comonomer units has a strong impact on nucleation of the majority phase spherulites. Increasing the amount of comonomer unit content leads to the formation of a higher concentration of spherulites with smaller sizes, indicating an increase in nucleation density. These results are very similar to those obtained previously with $\mathrm{LM}_{\mathrm{w}} \mathrm{BS}_{\mathrm{x}} \mathrm{CL}_{\mathrm{y}} \cdot{ }^{27}$ In both cases, adding comonomer enhances nucleation density during non-isothermal crystallization, thereby decreasing spherulitic size.

$\mathrm{HM}_{\mathrm{w}} \mathrm{BS}_{45} \mathrm{CL}_{55}$ is a random copolymer whose composition corresponds to the pseudoeutectic point. This is the only copolymer from those $\mathrm{HM}_{\mathrm{w}}$ random copolyesters prepared in 
this work that exhibited a double crystalline morphology. We have previously found that only those copolymers at the pseudo-eutectic point or pseudo-eutectic region are able to exhibit double crystallization. $1,16,27,29$

Figure 2a shows PBS-rich spherulites after the $\mathrm{HM}_{\mathrm{w}} \mathrm{BS}_{45} \mathrm{CL}_{55}$ sample was cooled from the melt and held at $20^{\circ} \mathrm{C}$ for $2 \mathrm{~h}$. At this temperature, the PCL-rich crystals are in the melt (see Figure 1a and 1b), and negative ring banded PBS-rich spherulites fill the microscope field. Therefore, upon cooling from a single phase melt, the PBS-rich phase is the first to crystallize forming spherulitic templates. These impinging spherulites contain lamellar crystals of the PBSrich phase with amorphous interlamellar regions of copolymer chains. A schematic diagram representing these spherulites is also included in Figure 2a, only the crystalline PBS-rich lamellae growing radially are represented.

Figure $2 \mathrm{~b}$ shows the result of quenching the sample shown in Figure $2 \mathrm{a}$ from $20{ }^{\circ} \mathrm{C}$ down to $-25^{\circ} \mathrm{C}$, a temperature at which the PCL-rich phase can crystallize within the intraspherulitic region of the PBS-rich phase (i.e., within the interlamellar regions of the spherulite). The crystallization of the PCL component can be observed in Figure $2 b$, as the birefringence increases in the sample and the spherulitic structures look brighter (compare the close up spherulite shown in Figure 2a, before PCL crystallization with that in Figure 2b, after PCL-rich crystals are formed).

The PBS-rich phase crystals templates the crystalline superstructural morphology (blue lamellae in schematic model of Figure 2a), and the PCL-rich crystals can only form upon cooling from the melt (see red inner lamellae in Figure 2b) inside the pre-formed templates. Hence, in Figure 2b we have examples of double crystalline spherulites. 
Figure 2. PLOM micrographs for $\mathrm{HM}_{\mathrm{w}} \mathrm{BS}_{45} \mathrm{CL}_{55}$ copolymer with schematic models: (a) the sample was cooled from the melt and held at $20^{\circ} \mathrm{C}$ for $2 \mathrm{~h}$, (b) micrograph taken after the sample was quenched rapidly from $20^{\circ} \mathrm{C}$ to $-25^{\circ} \mathrm{C}$ and held $20 \mathrm{~min}$ at $-25^{\circ} \mathrm{C}$, and (c) sample was reheated to $20^{\circ} \mathrm{C}$. In the schematic models (bottom left hand side), the blue lines indicate PBS-rich lamellae while the red lines correspond to PCL-rich lamellae and the pink background indicates the amorphous regions of homogeneous mixtures of copolymer chains. 
Similar double crystalline superstructures have been observed in PBS-ran-PBAz copolyester at the pseudo-eutectic composition ${ }^{29}$ and in weakly segregated or melt mixed block copolymers. ${ }^{30,31}$

Figure $2 \mathrm{c}$ shows the morphology after the sample was reheated up to $20^{\circ} \mathrm{C}$ to melt the PCL-rich phase crystals. The field remains full with PBS-rich phase spherulites as expected since the molten PCL-rich phase is within the intraspherulitic regions of the PBS phase.

\section{Influence of molecular weight on crystallization and melting}

In this work, only one of the prepared compositions fell within the eutectic point (i.e., $\mathrm{HM}_{\mathrm{w}} \mathrm{BS}_{45} \mathrm{CL}_{55}$ ), as signaled by the presence of two crystalline phases. ${ }^{1}$ When the composition was changed to $\mathrm{BS}_{38} \mathrm{CL}_{62}$ (i.e., 7 molar \% more $\mathrm{CL}$ units in the copolymer with respect to the eutectic composition), then only the PCL-rich crystalline phase was formed. On the other hand, when it was changed to $\mathrm{BS}_{51} \mathrm{CL}_{49}$ (i.e., 6 molar \% less $\mathrm{CL}$ units than the eutectic composition) just the PBS-rich crystalline phase was formed, see Figure 1.

In the $\mathrm{LM}_{\mathrm{w}} \mathrm{BS}_{\mathrm{x}} \mathrm{CL}_{\mathrm{y}}$ case, three copolymers were inside the eutectic region $\left(\mathrm{BS}_{45} \mathrm{CL}_{55}\right.$, $\mathrm{BS}_{48} \mathrm{CL}_{52}$, and $\left.\mathrm{BS}_{54} \mathrm{CL}_{46}\right)$ as for these copolyesters two characteristic crystallization and melting peaks were observed. ${ }^{27}$ These three copolyesters span a CL composition range of 11 molar \%. Therefore, lower molecular weights apparently cause a widening of the pseudo-eutectic region in these isodimorphic systems. However, more compositions would have to be prepared to confirm this trend.

A comparison between the non-isothermal crystallization and melting of both sets of samples can be observed in Figure 3. As it is well known, in homopolymers, $T_{m}$ values increase with chain length until they saturate at high molecular weights. Figure 3 clearly shows that in 
these random copolyesters, both $T_{c}$ and $T_{m}$ are not affected by the changes in molecular weight. This result can be explained as in random copolymers, the comonomeric content and its distribution can dominate the crystallizable sequence selection during crystallization. ${ }^{12,} 32$ As both types of copolymers are nearly perfectly random, the size of the average crystallizable sequence is clearly much lower than the lowest $M_{w}$ copolymer chain length.

Figures $3 \mathrm{c}$ and $3 \mathrm{~d}$ show how the enthalpy of crystallization and melting (normalized by the content of the crystallizable phase) depend on copolymer composition. Figure $3 \mathrm{e}$ plots the degree of crystallinity (obtained from the DSC heating scans) as a function of composition. Two important observations can be made from these plots.

Firstly, the degree of crystallinity displays a pseudo-eutectic point when plotted as a function of composition. This is a consequence of the influence of comonomer exclusion during crystallization. As the amount of comonomer increases for a particular crystalline phase (either PBS-rich or PCL-rich crystalline phases), comonomer exclusion (which predominates over comonomer inclusion) interferes with crystallization, as the length of crystallizable sequences (which can include a limited number of the second comonomer units) decreases. As a consequence, the degree of crystallinity decreases when the minority comonomer content increases for any given crystalline phase.

Secondly, Figures 3c-3e show that the lower molecular weight samples can develop a higher degree of crystallinity than the higher molecular weight copolymers. This is due to their higher non-isothermal crystallization rate, which stems from the faster diffusion of smaller molecules.

The crystallinity of copolyesters has been determined by dividing the observed heat of fusion $\Delta H_{m}$ by the theoretical value for $100 \%$ crystalline polymer. The theoretical $\Delta H_{m}^{0}$ values for PBS and PCL are 110.3 and $139.5 \mathrm{~J} / \mathrm{g},{ }^{33,34}$ respectively. The data for the copolymers plotted 
in Figure 3e show that the crystallinity levels are sensitive to molecular weight, as well as, to the copolymer composition.
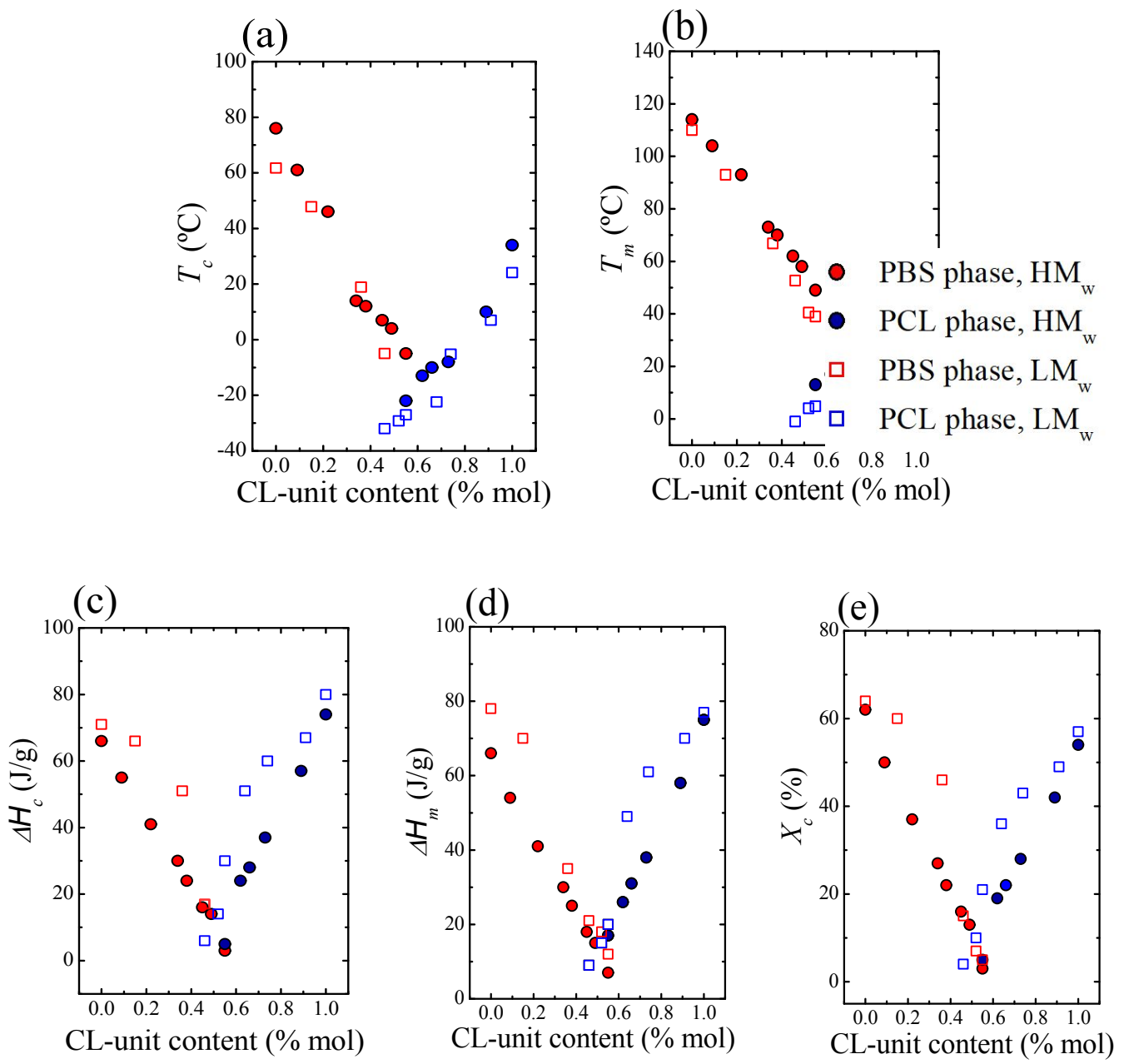

Figure 3. Composition dependence of (a) peak crystallization temperature $T_{c}$ (b), peak melting temperature $T_{m}$, (c) crystallization enthalpy $\Delta H_{\mathrm{c}}$, (d) melting enthalpy $\Delta H_{\mathrm{m}}$, and (e) crystallization degree $X_{c}$ of the indicated samples.

\section{Influence of molecular weight on $T_{g}$}


Random copolymers form a single phase in the melt and in the amorphous state. They exhibit a single $T_{g}$ that depends on composition. Figure 4 shows how the $T_{g}$, in both copolymer groups (low and high molecular weight), is a strong function of composition and molecular weight. For both homopolymers and random copolymers, $T_{g}$ values increase with molecular weight until they saturate at a limiting molecular weight value. This trend is explained by the higher fraction of chain ends present in lower $M_{w}$ polymers that can increase the free volume. As the $M_{w}$ increases the effect of chain ends is diluted and it becomes negligible for very long chains. ${ }^{35}$

In random copolyesters, $T_{g}$ is usually a monotonic function of composition that can be predicted by semi-empirical equations. In this work, the Gordon-Taylor equation ${ }^{36}$ (i.e., Equation 1), was found to adequately describe the experimental data for both types of samples $\left(\mathrm{LM}_{\mathrm{w}}\right.$ and $\left.\mathrm{HM}_{\mathrm{w}}\right)$

$$
T_{g, \text { copo }}=\frac{w_{1} T_{g, 1}+k\left(1-w_{1}\right) T_{g, 2}}{w_{1}+k\left(1-w_{1}\right)}
$$

where $T_{g, l}$ and $T_{g, 2}$ are the glass transition temperature of the homopolyesters, $w_{l}$ the respective mass fraction of one of the components and $k$ the Gordon-Taylor parameter.

PBS and PCL homopolymers were used for comparison purposes only. In the case of PCL, the values of $M_{w}$ do not differ much $(16.3$ and $17.4 \mathrm{~kg} / \mathrm{mol})$ but their dispersities are quite different ( 2 and 3.2 for the low and high $M_{w}$ samples respectively). This may explain the differences in $T_{g}$ observed in Figure 4, as the PCL sample with a lower dispersity probably contains a higher density of chain ends.

In the case of PBS homopolymer, even though the differences in $M_{w}$ between the samples are larger than in the case of PCLs, the observed difference in $T_{g}$ is very small. We do 
not have an explanation for this result. It should be considered that as the crystallinity increases (the homopolymers have crystallinity degrees around 50\%), determination of $T_{g}$ values by DSC become increasingly difficult, especially if a rigid amorphous phase develops in the material. Further studies would be needed that are outside the scope of the present investigation.

As shown in Figure 4, the Gordon-Taylor equation fits well the experimental data with $k=0.62$ for $\mathrm{HM}_{\mathrm{w}}$ samples and $k=0.23$ for $\mathrm{LM}_{\mathrm{w}}$ samples. The term $k$ in Equation 1 is a parameter whose value depends on the change in thermal expansion coefficient $(\alpha)$ of the components as they change from the glassy (amorphous) to the liquid (rubbery) form, during the glass transition. Accordingly, $k=\left(V_{2} / V_{1}\right)\left(\Delta \alpha_{2} / \Delta \alpha_{1}\right)^{36}$, where $V$ represents the specific volume at the corresponding $T_{g}$. By the Simha-Boyer law ${ }^{37}\left(\Delta \alpha . T_{g}=\right.$ constant $)$ we obtain $k \approx\left(V_{2} T_{g 1} / V_{l} T_{g 2}\right)^{38}$. As far as we are aware, density values for the PBS and PCL homopolymers at the glass transition temperatures are not available. Further studies would be needed to understand in detail the differences in $k$ values beyond a simple fit parameter ${ }^{39}$, however, they are beyond the scope of the present study.

If a comparison is made between Figure $3 \mathrm{~b}$ and Figure 4, a very interesting characteristic of isodimorphic random copolymers can be appreciated. These copolymers allow a separate control of $T_{m}$ and $T_{g}$, both as a function of composition and molecular weight. While in homopolymers both $T_{m}$ and $T_{g}$ follow similar empirical correlations as molecular weight increases, in isodimorphic copolymers $T_{g}$ is a function of $M_{w}$ while $T_{m}$ is independent of $M_{w}$, as long as the average length of the crystallizable sequences is smaller than the molecular weights of the random copolymers under consideration. 
- Experimental-HM Gordon-Taylor fitting curve $(\mathrm{k}=0.62)$

口 Experimental-LM

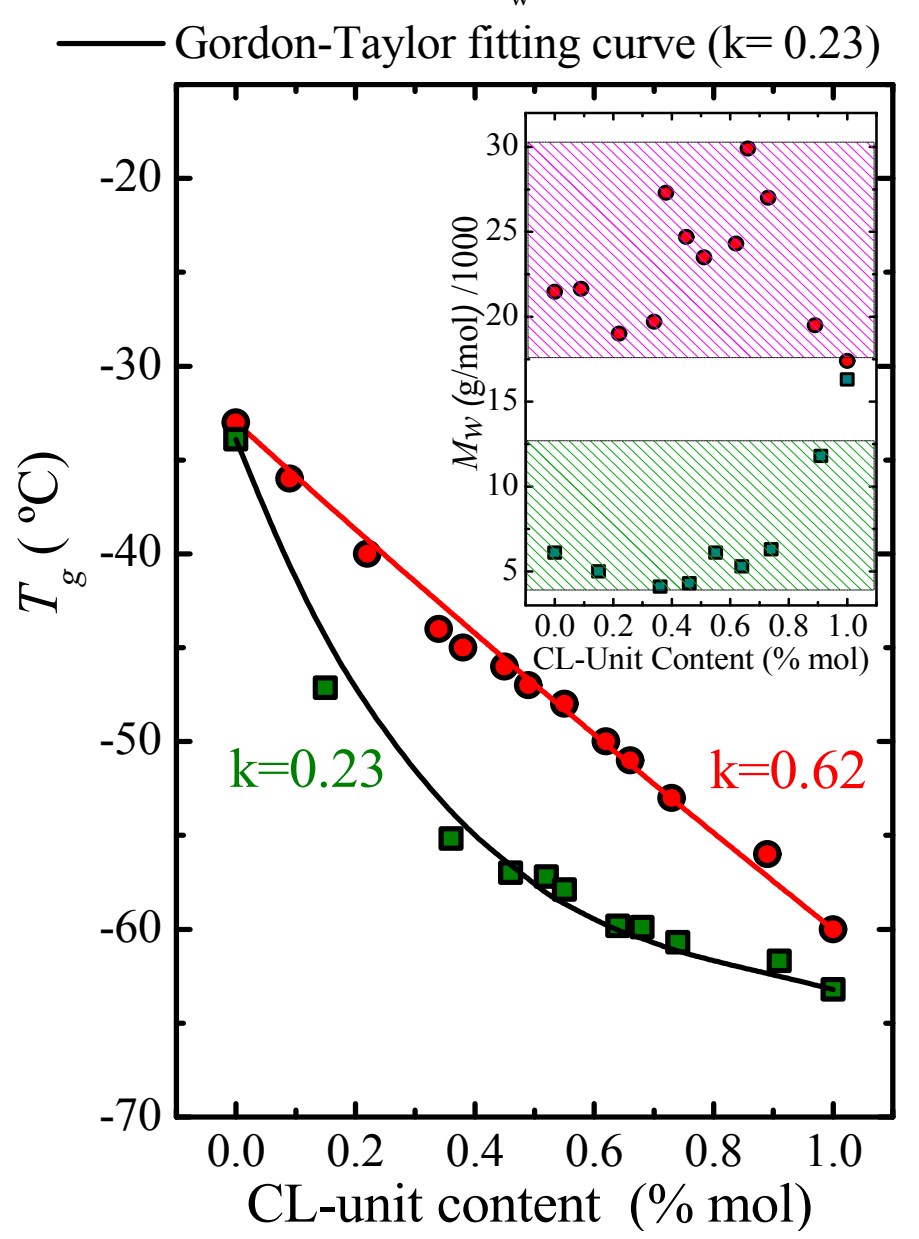

Figure 4. Glass transition temperature as a function of composition for the indicated samples. The inset plots show the $M_{w}$ values of the samples.

\section{Influence of composition on lamellar thickness}

Figures 5a-5d show SAXS diffractograms for all $\mathrm{HM}_{\mathrm{w}}$ and $\mathrm{LM}_{\mathrm{w}}$ PBS-ran-PCL copolymers and parent homopolymers measured at $-60^{\circ} \mathrm{C}$, after the samples were cooled from the melt at $10{ }^{\circ} \mathrm{C} / \mathrm{min}$. In all cases, a single scattering peak can be observed. This reflection 
arises from the X-ray scattering produced by lamellar stacks within the spherulitic structures in the sample. From the position of this peak, the long period $(L)$ can be calculated.

In two samples $\left(\mathrm{LM}_{\mathrm{w}} \mathrm{BS}_{45} \mathrm{CL}_{55}\right.$ and $\left.\mathrm{HM}_{\mathrm{w}} \mathrm{BS}_{45} \mathrm{CL}_{55}\right)$, no $\mathrm{SAXS}$ signal was detected, as these samples crystallize a very small amount (approximately $10 \%$ or less) during cooling at 10 ${ }^{\circ} \mathrm{C} / \mathrm{min}$ and there was probably not enough lamellar stacking or the long period was so large (as the sample is $90 \%$ amorphous) that it fell at angles that are too low for detection.

Figure 5e shows a plot of the lamellar stacks long period determined at $-60{ }^{\circ} \mathrm{C}$ as a function of composition for $\mathrm{HM}_{\mathrm{w}}$ and $\mathrm{LM}_{\mathrm{w}}$ copolyesters. For both $\mathrm{HM}_{\mathrm{w}}$ and $\mathrm{LM}_{\mathrm{w}}$ BS-ran-CL, there is an increase in long period in the PBS rich phase, as the amount of CL units increase in the copolymer. On the right hand side of the pseudo-eutectic point the trend in the data is not so clear in terms of long period values (as they depend on crystallinity, see below).

Another important result is that the long period (Figure 5e), which is inversely proportional to crystallinity, is higher for the $\mathrm{HM}_{\mathrm{w}}$ samples in the PBS rich phase, as they contain a higher amount of interlamellar amorphous regions (i.e., the $X_{c}$ values are lower for HMw copolymers as shown in Figure 3e). While Figure $3 \mathrm{~b}$ showed how $T_{m}$ values exhibited almost no difference between low and high $M_{w}$ samples (for $\mathrm{HM}_{\mathrm{w}}$ samples $T_{m}$ values are slightly higher than for $\mathrm{LM}_{\mathrm{w}}$ copolymers), the crystallinity in $\mathrm{HM}_{\mathrm{w}}$ copolymers (Figure 3e) was substantially lower than for low $M_{w}$ copolymers.

The average crystalline lamellar thickness, $l_{c}$, of $\mathrm{LM}_{\mathrm{w}}$ and $\mathrm{HM}_{\mathrm{w}}$ PS-ran-PCL samples at $-60{ }^{\circ} \mathrm{C}$ were calculated by the approximation: $l_{c}=L . X_{c}$ (where $X_{c}$ is the crystallinity degree and $L$ the long period) and plotted as a function of CL-content in Figure $5 f$. It can be observed that the lamellar thickness values, within the experimental errors of the measurements, are quite similar between low and high $M_{w}$ samples (the lamellar thickness are slightly higher, only about 
$1 \mathrm{~nm}$ difference, for $\mathrm{HM}_{\mathrm{w}}$ copolymers in consistency with the $T_{m}$ values trend plotted in Figure $3 b)$.

The $l_{c}$ values for PBS-rich and PCL-rich copolymers decrease with increases of comonomer unit content and in contrast, the intervening amorphous layer thickness, $l_{a}$, values $\left(l_{a}=L-l_{c}\right)$ increase with comonomer content. These trends in $l_{a}$ and $l_{c}$ are fully consistent with the changes of $T_{m}$ and $X_{c}$ values as a function of composition presented in Figure 3. In fact, for both series of copolymers, $l_{a}$ and $l_{c}$ values also exhibit a pseudo-eutectic-like behavior as a function of composition. The results can be explained if we consider that as comonomer content increases in each phase (i.e., PCL rich crystalline phase or PBS rich crystalline phase) exclusion of the second comonomer predominates. Comonomer exclusion limits the average length of the crystallizable sequences and therefore the lamellar thickness $\left(l_{c}\right)$ decreases. Comonomer exclusion also limits the amount of crystals that can be formed and the degree of crystallinity decreases with CL units content while $L$ and $l_{a}$ increase.

Moreover, Figure $5 \mathrm{f}$ shows that the molecular weight (in the range explored here) does not affect the lamellar thickness values $\left(l_{c}\right)$. These results support our conclusion that in these isodimorphic random copolymers, the random sequence of linear crystallizable chains controls the length of the crystallizable sequences (which is always smaller than the average chain length of $\mathrm{LM}_{\mathrm{w}}$ copolymer chains), and therefore the thickness of the lamellae formed. As a consequence, $T_{m}$ values do not significantly change (as they are directly proportional to the lamellar thickness values, as predicted by the Gibbs-Thompson equation), when the molecular weight of these random copolyesters is increased from the low $M_{w}$ to the high $M_{w}$ copolymer series. 
(a)

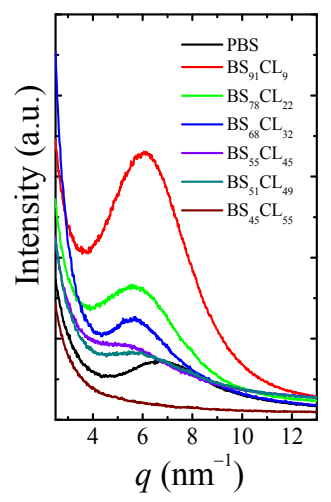

(b)

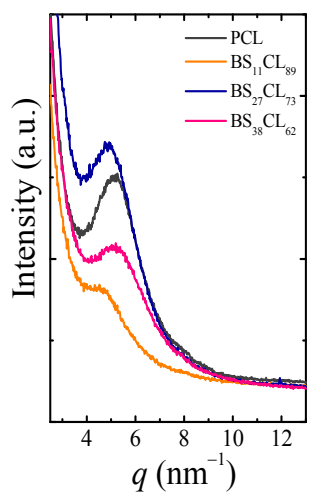

(c)

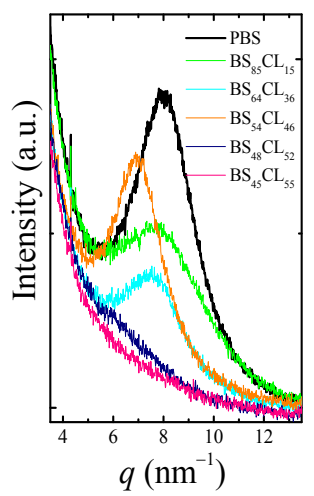

(d)

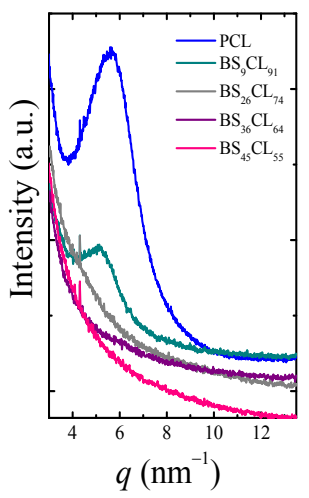

(e)

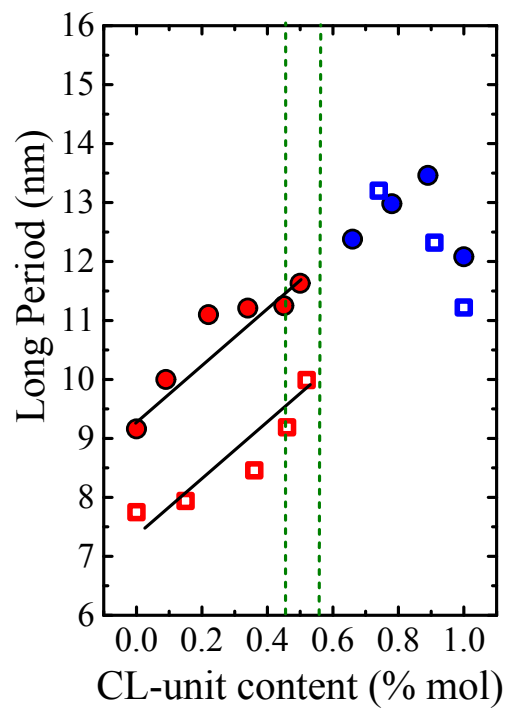

(f)

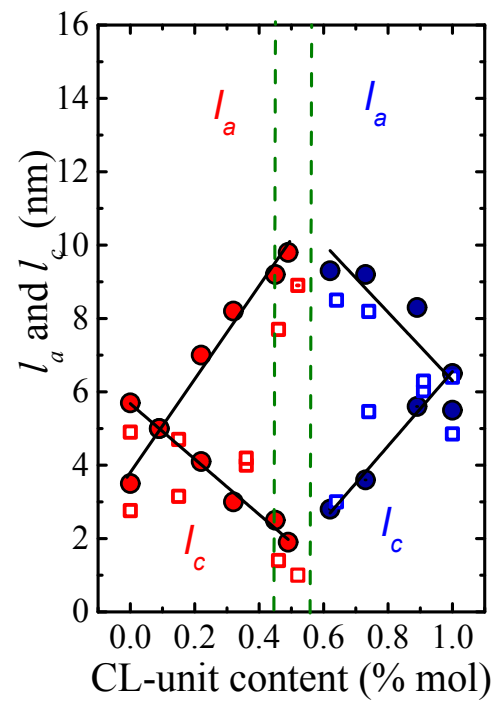

- PBS phase, $\mathrm{HM}_{\mathrm{w}}$

- PCL phase, $\mathrm{HM}_{\mathrm{w}}$

- PBS phase, $\mathrm{LM}_{\mathrm{w}}$

$\square \quad$ PCL phase, $\mathrm{LM}_{\mathrm{w}}$

Figure 5. SAXS diffractograms for (a) $\mathrm{HM}_{\mathrm{w}}$-PBS-rich phases, (b) $\mathrm{HM}_{\mathrm{w}}$-PCL-rich phases, (c) $\mathrm{LM}_{\mathrm{w}}$-PBS-rich phases and (d) $\mathrm{LM}_{\mathrm{w}}-\mathrm{PCL}$-rich phases at $-60^{\circ} \mathrm{C}$. (e) Long period values as a function of composition for $\mathrm{HM}_{\mathrm{w}}$ and $\mathrm{LM}_{\mathrm{w}}$ BS-ran-CL. (f) Average lamellar thickness $\left(l_{c}\right)$ and amorphous layer thickness $\left(l_{a}\right)$ for $\mathrm{HM}_{\mathrm{w}}$ and $\mathrm{LM}_{\mathrm{w}} \mathrm{BS}$-ran-CL. Solid lines are drawn to guide the eye. 


\section{Influence of the cooling rate on non-isothermal crystallization for compositions close and at the pseudo-eutectic point}

In order to better understand the sequential and coincident crystallization processes at and near the pseudo-eutectic point, rate-dependent experiments were performed. Figure 6a, 6b, and $6 \mathrm{c}$ show cooling scans from the melt at different cooling rates corresponding to the following $\mathrm{HM}_{\mathrm{w}}$ copolymers: $\mathrm{BS}_{51} \mathrm{CL}_{49}, \mathrm{BS}_{45} \mathrm{CL}_{55}$ and $\mathrm{BS}_{38} \mathrm{CL}_{62}$, respectively. These compositions are located left of the pseudo-eutectic point, at the pseudo-eutectic point, and right of the pseudo-eutectic point. Subsequent heating scans performed at the constant rate of 20 ${ }^{\circ} \mathrm{C} / \mathrm{min}$ are shown in Figures $6 \mathrm{~d}, 6 \mathrm{e}, 6 \mathrm{f}$. Similar experiments were performed with the $\mathrm{LM}_{\mathrm{w}}$ samples, and they are presented in the Supplementary Information (Figure SI-6) and commented below when relevant.

At the pseudo-eutectic point of $\mathrm{HM}_{\mathrm{w}}$ copolyesters, Figure $6 \mathrm{~b}$ shows that when the $\mathrm{BS}_{45} \mathrm{CL}_{55}$ copolymer is cooled at a very slow rate $\left(0.5\right.$ and $\left.1{ }^{\circ} \mathrm{C} / \mathrm{min}\right)$, only the PBS-rich phase can crystallize, as indicated by the subsequent DSC scan (see Figure 6e), where a single melting peak (with some bimodal character) at temperatures higher than the melting point of the PCLrich phase can be observed. In this sample, when the PBS-rich phase has enough time to crystallize during cooling, it inhibits the crystallization of the PCL-rich phase at lower temperatures. This is probably due to confinement effects, as the PBS-rich phase crystallizes from the melt into well-develop spherulitic superstructures (of small size according to PLOM observations, see Figure SI-5) formed by radially growing PBS-rich lamellae. Upon further cooling, the PCL-rich lamellae would have to crystallize in the interlamellar regions of these PBS-rich spherulitic templates. Similar results were obtained for poly[(butylene succinate)-ran- 
(a)

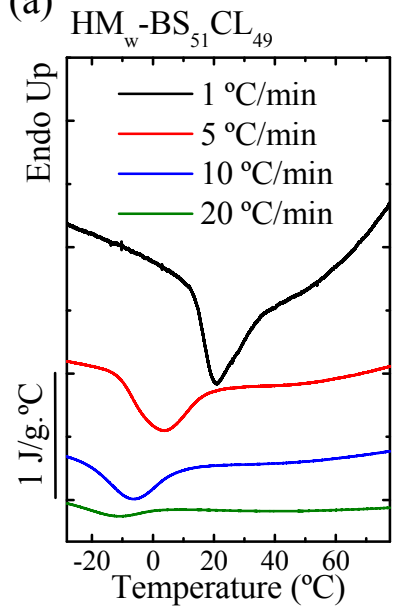

(d)

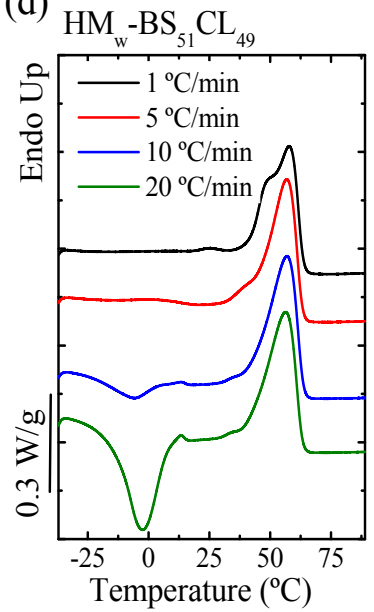

(b)

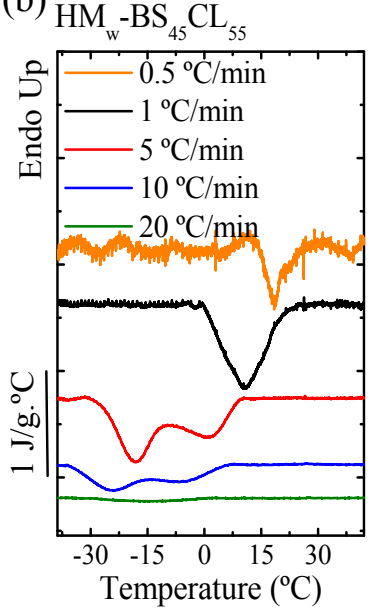

(e) $\mathrm{HM}_{\mathrm{w}}-\mathrm{BS}_{45} \mathrm{CL}_{55}$

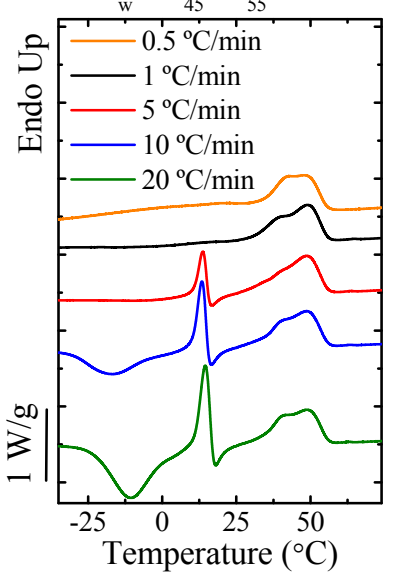

(c)

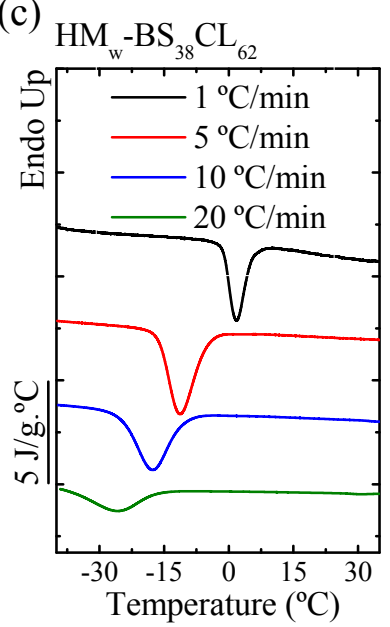

(f)

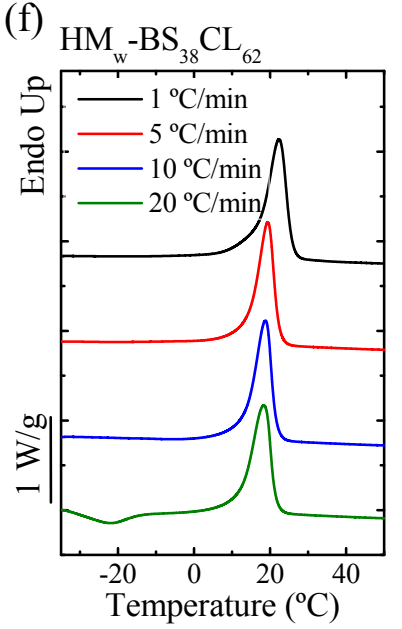

Figure 6. For $\mathrm{HM}_{\mathrm{w}}$ copolyesters, $\mathrm{BS}_{51} \mathrm{CL}_{49}$ (a), $\mathrm{BS}_{45} \mathrm{CL}_{55}(\mathrm{~b})$, and $\mathrm{BS}_{38} \mathrm{CL}_{62}$ (c) cooling scans to $-60{ }^{\circ} \mathrm{C}$ at different cooling rates and (d), (e), (f) are subsequent heating scans performed at $20{ }^{\circ} \mathrm{C} / \mathrm{min}$ for each copolyester.

At the pseudo-eutectic region, $\mathrm{LM}_{\mathrm{w}}$ copolyesters exhibited some differences with $\mathrm{HM}_{\mathrm{w}}$ samples. When the cooling rate was either slow or intermediate $\left(1,5\right.$ and $\left.10^{\circ} \mathrm{C}\right)$ both $\mathrm{PBS}$ and PCL-rich phases were able to crystallize, as indicated by the subsequent DSC scans (see Figures 
SI-6 in the Supplementary Info). However, the amount of PCL-rich phase formed was still dependent on the cooling rate. As the cooling rate decreased, the amount of PBS-rich phase formed was much higher than that of PCL-rich phase. This increased ability of the PCL-rich phase to crystallize can be ascribed to the lower $\mathrm{M}_{\mathrm{w}}$ of these copolyester samples which have demonstrated higher crystallization ability compatible with their increased $X_{c}$ values in comparison to $\mathrm{HM}_{\mathrm{w}}$ samples (Figure 3e).

The DSC cooling scans for $\mathrm{HM}_{\mathrm{w}}$ samples in Figure $6 \mathrm{~b}$ performed at $5^{\circ} \mathrm{C} / \mathrm{min}$ shows a bimodal crystallization exotherm. When the subsequent heating DSC scan is examined in Figure $6 \mathrm{e}$, the sample that was cooled at $5^{\circ} \mathrm{C} / \mathrm{min}$ shows a clear but small melting peak at around $10{ }^{\circ} \mathrm{C}$, that corresponds to the melting of the PCL-rich phase. Notice the absence of cold crystallization before the PCL-rich crystals melt. At higher temperatures, a cold crystallization exotherm (which could be incomplete as a result of an overlap with the PCL-rich crystalline phase melting endotherm) of the PBS-rich phase can be observed, followed by the melting of the PBS-rich phase crystals. The DSC evidence clearly indicates that at $5^{\circ} \mathrm{C} / \mathrm{min}$, both PBS and PCL-rich phases are able to crystallize, but judging by their normalized melting enthalpies, the PBS-rich phase can crystallize much more (for PBS-rich phase $\Delta H_{\mathrm{m}}=24 \mathrm{~J} / \mathrm{g}$ and PCL-rich phase $\Delta H_{m}=5 \mathrm{~J} / \mathrm{g}$ ). A similar bimodal crystallization behavior occurred during cooling for compositions at the pseudo-eutectic region for $\mathrm{LM}_{\mathrm{w}}$ copolyesters in Figure SI-6 b, c and d that were performed at $1^{\circ} \mathrm{C} / \mathrm{min}$ and $5^{\circ} \mathrm{C} / \mathrm{min}$ cooling rate.

Figure 7a shows PLOM micrographs taken during cooling from the melt at $5 \% \mathrm{~min}$ for the $\mathrm{BS}_{45} \mathrm{CL}_{55} \mathrm{HM}_{\mathrm{w}}$ copolymer sample, whose composition corresponds to the pseudo-eutectic point. At $0{ }^{\circ} \mathrm{C}$, a series of well-defined negative spherulites (with sizes close to $10 \mu \mathrm{m}$ ) with clear Maltese crosses can be seen, that correspond to the PBS-rich phase (as this is the first 
component to crystallize, as corroborated by WAXS results presented below), surrounded by a melt of copolyester chains. Upon further cooling, at around $-10^{\circ} \mathrm{C}$, the PCL-rich phase starts to crystallize and additional small birefringent structures (circa $2 \mu \mathrm{m}$ ) were observed (together with small changes in the birefringence of the pre-existing spherulites, indicating that some PCL crystallization must have occurred inside the PBS-rich spherulitic templates, in analogy to Figure 2). Finally, at $-30^{\circ} \mathrm{C}$, two populations of spherulites coexist (although they are difficult to appreciate in Figure $7 \mathrm{a}$, because of the scale of the micrograph), some are bigger (12 $\mu \mathrm{m}$ aprox) and are the double crystalline spherulites formed during cooling from the melt filled with both PBS-rich and PCL-rich lamellae. The second type are much smaller spherulites formed at temperatures of $-10{ }^{\circ} \mathrm{C}$ and lower, which must also correspond to double crystalline spherulites, although they may contain a higher population of PCL lamellae because they were formed at lower temperatures. 
(a) $5{ }^{\circ} \mathrm{C} / \mathrm{min}$
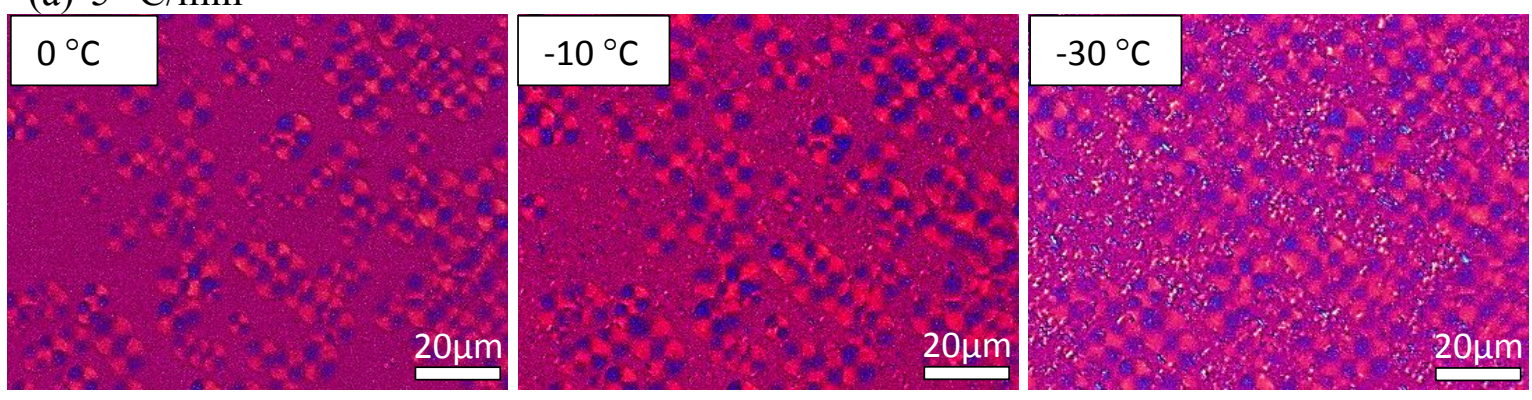

(b) $10{ }^{\circ} \mathrm{C} / \mathrm{min}$
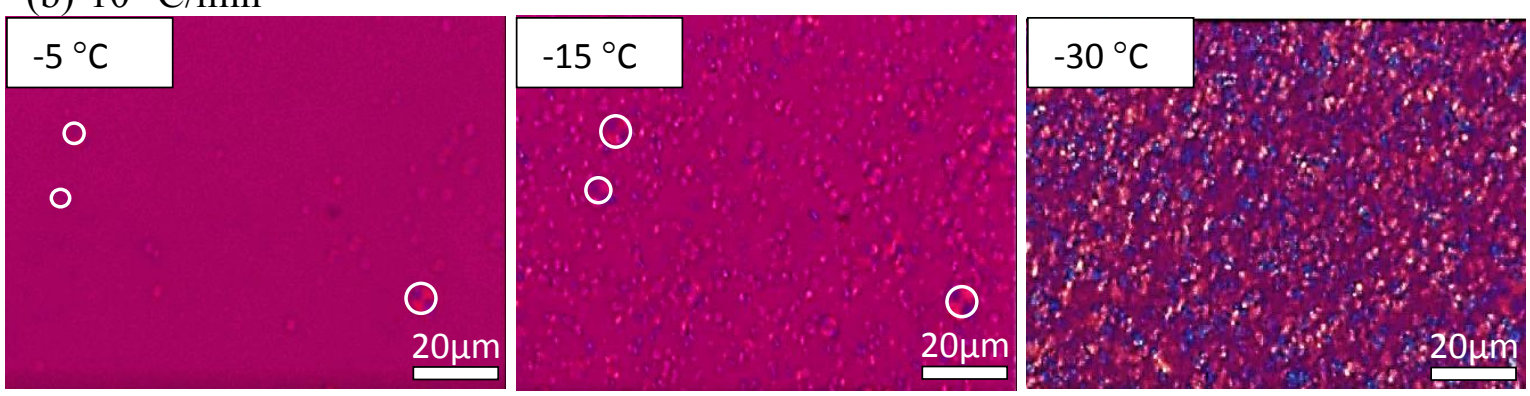

(c) $20^{\circ} \mathrm{C} / \mathrm{min}$
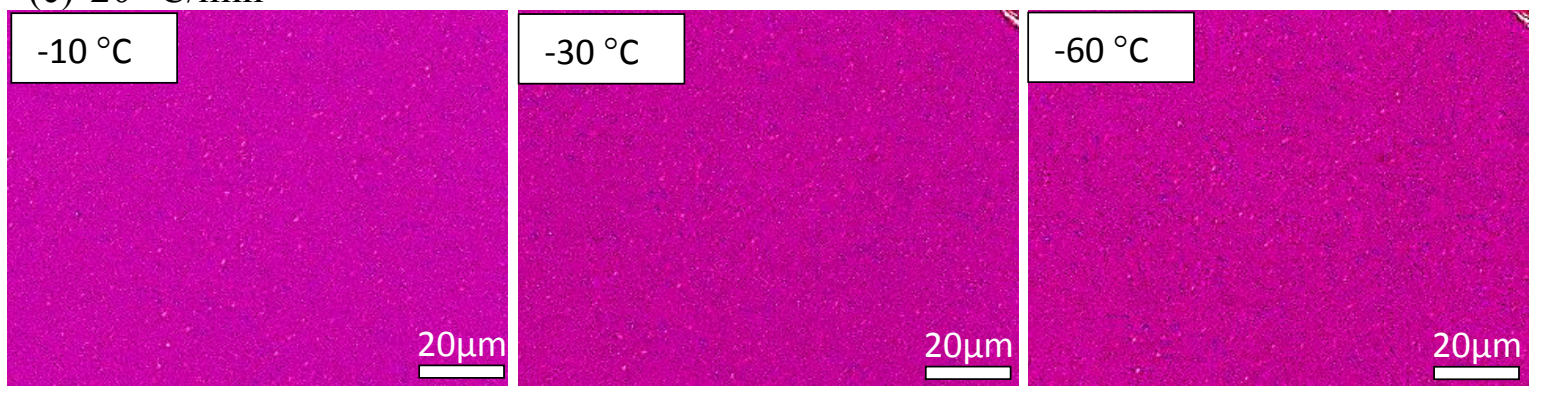

Figure 7. PLOM micrographs taken during cooling from the melt at different cooling rates for the $\mathrm{HM}_{\mathrm{w}} \mathrm{BS}_{45} \mathrm{CL}_{55}$ copolyester sample (whose composition corresponds to the pseudo-eutectic point): (a) $5{ }^{\circ} \mathrm{C} / \mathrm{min}$, (b) $10{ }^{\circ} \mathrm{C} / \mathrm{min}$, and (c) $20^{\circ} \mathrm{C} / \mathrm{min}$. The white scale bar is equal to $20 \mu \mathrm{m}$. The white circles in Figure $7 \mathrm{~b}$ were drawn to highlight the presence of the few PBS-rich spherulites that were formed.

As the cooling rate increases to $10^{\circ} \mathrm{C} / \mathrm{min}$, the subsequent heating scans (performed always at $20^{\circ} \mathrm{C} / \mathrm{min}$ ) in Figure 6e show cold crystallization exotherms below the melting 
transition of the PCL-rich phase melting. Figure $7 \mathrm{~b}$ shows three PBS-rich phase spherulites (white circles were drawn to guide the eye) at higher temperature $\left(-5^{\circ} \mathrm{C}\right)$ and at $-15^{\circ} \mathrm{C}$ smaller birefringent structures appear that must correspond to PCL-rich phase spherulites. As WAXS experiments will demonstrate below, only PCL-rich crystals are detected at this cooling rate (10 $\left.{ }^{\circ} \mathrm{C} / \mathrm{min}\right)$.

At an even higher cooling rate of $20^{\circ} \mathrm{C} / \mathrm{min}$, for both $\mathrm{HM}_{\mathrm{w}}$ and $\mathrm{LM}_{\mathrm{w}}$ copolyesters, the PBS-rich phase cannot crystallize at all during cooling, and only PCL-rich crystals are formed (see Figure $6 \mathrm{~b}$ and 7c for the only HMw pseudo-eutectic composition copolymer; and Figures SI-6b, SI-6c, SI-6d for the 3 LMw pseudo-eutectic composition copolymers). The birefringent structures formed at $20^{\circ} \mathrm{C} / \mathrm{min}$, Figure 7c, corresponding to PCL-rich crystals are very small, with sizes barely discernible by PLOM.

In these interesting eutectic copolyester samples $\left(\mathrm{HM}_{\mathrm{w}} \mathrm{BS}_{45} \mathrm{CL}_{55}\right.$ shown in Figures $6 \mathrm{~b}$ and Figure 7 and $\mathrm{LM}_{\mathrm{w}} \mathrm{BS}_{54} \mathrm{CL}_{46}, \mathrm{BS}_{48} \mathrm{CL}_{52}, \mathrm{BS}_{45} \mathrm{CL}_{55}$ shown in the Supplementary Information), the control of the cooling rate is crucial, as the crystallinity and type of crystals formed strongly depend on this parameter.

Similar experiments were performed for two other copolymer samples, $\mathrm{HM}_{\mathrm{w}} \mathrm{BS}_{51} \mathrm{CL}_{49}$ whose composition fall to the left of the pseudo-eutectic point in Figure $1 \mathrm{~b}$, and $\mathrm{HM}_{\mathrm{w}} \mathrm{BS}_{38} \mathrm{CL}_{62}$, whose composition fall to the right of the pseudo-eutectic point. In both cases, only one phase was able to crystallize (i.e., the PBS-rich phase in $\mathrm{HM}_{\mathrm{w}} \mathrm{BS}_{51} \mathrm{CL}_{49}$ and the PCL-rich phase in $\mathrm{HM}_{\mathrm{w}} \mathrm{BS}_{38} \mathrm{CL}_{62}$ ) and the increase in cooling rate just caused a shift of the crystallization exotherm to lower temperatures as expected (together with a reduction in crystallization enthalpy), see Figures $6 \mathrm{a}$ and $6 \mathrm{c}$. The subsequent heating scans are shown in Figures $6 \mathrm{~d}$ and $6 \mathrm{f}$ 
(performed at a constant heating rate of $20^{\circ} \mathrm{C} / \mathrm{min}$ ). The expected melting of the corresponding crystallizable phase (only one phase) can be observed, as well as cold crystallization in samples rapidly cooled. Parallel results were found for $\mathrm{LM}_{\mathrm{w}}$ samples outside the pseudo-eutectic region and are shown in the Supplementary Information (see Figures SI-6a, 6e, 6f and 6j).

In summary, the crystallization of the PBS-rich and PCL-rich crystal phases have a strong dependence on cooling rate at the pseudo-eutectic point for both $\mathrm{LM}_{\mathrm{w}}$ and $\mathrm{HM}_{\mathrm{w}}$ copolymers. If the cooling rate is low enough (lower than $5^{\circ} \mathrm{C} / \mathrm{min}$ ), as the PBS-rich phase forms first during cooling from the melt, it produces spherulitic templates that had time to fully develop during slow cooling. The PCL-rich phase would have to crystallize within the PBSrich interlamellar space and this does not happen in the $\mathrm{HM}_{\mathrm{w}}$ copolymers, because of confinement effects.

When the cooling rate is intermediate $\left(5^{\circ} \mathrm{C} / \mathrm{min}\right)$, the PBS-rich phase can still form spherulitic templates (as indicated in Figure 7a), but they may not be as well structured as those formed at lower cooling rates, and the PCL-rich phase is able to develop some crystallinity. At a faster cooling rate of $10{ }^{\circ} \mathrm{C} / \mathrm{min}$, only a few spherulites of the PBS-rich phase can form (marked by white circles in Figure 7b), and the PCL-phase crystallizes at lower temperatures and constitutes the majority of the crystal phase of the material.

At cooling rates of $20^{\circ} \mathrm{C} / \mathrm{min}$ and faster, the PBS-rich phase cannot crystallize at all during cooling, giving the PCL-rich phase the possibility to develop some crystallinity during cooling (see Figure 7c). Upon subsequent heating, the PCL-rich phase can undergo coldcrystallization and enhances its crystallinity content. At even higher temperatures, the PBS-rich phase cold-crystallizes while the PCL-rich crystals melt. 

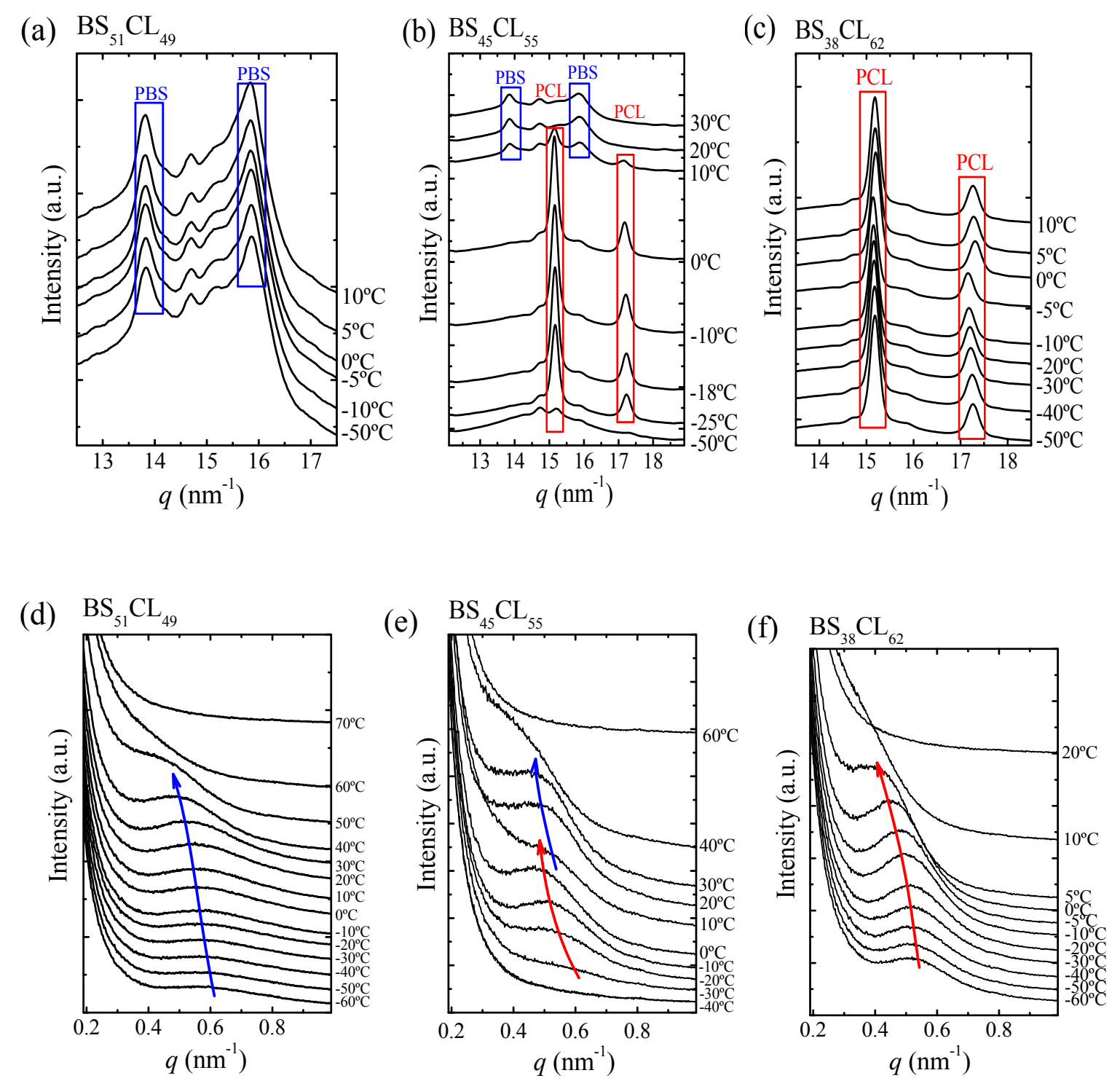

Figure 8. (a), (b), and (c) are WAXS patterns and (d), (e), and (f) are SAXS patterns during heating at $10^{\circ} \mathrm{C} / \mathrm{min}$ (after cooling from the melt at $10^{\circ} \mathrm{C} / \mathrm{min}$ ) for the indicated copolyesters.

We performed in situ synchrotron SAXS/WAXS experiments for the 3 selected $\mathrm{HM}_{\mathrm{w}}$ samples shown in Figure 6. These experiments were performed only at $10{ }^{\circ} \mathrm{C} / \mathrm{min}$ during both cooling and subsequent heating from the melt. The results obtained during heating at $10^{\circ} \mathrm{C} / \mathrm{min}$ 
(i.e., second heating, as the samples were first molten and then controlled cooled from the melt at $10{ }^{\circ} \mathrm{C} / \mathrm{min}$ ) are presented in Figure 8, where selected diffractograms were chosen for a series of temperatures.

In the case of the two $\mathrm{HM}_{\mathrm{w}}$ copolymer samples at each side of the pseudo-eutectic point, WAXS demonstrates that only one type of crystals is present, i.e., PBS like crystals for the $\mathrm{BS}_{51} \mathrm{CL}_{49}$ sample and PCL like crystals for the $\mathrm{BS}_{38} \mathrm{CL}_{62}$. These results are consistent with the previously discussed DSC data (Figure $6 \mathrm{~d}$ and $6 \mathrm{f}$, see the curves at $10{ }^{\circ} \mathrm{C} / \mathrm{min}$ ). SAXS curves for these same copolymers also exhibit the expected behavior, as the SAXS maximum shifts to lower q values (higher long periods) as temperature is increased (see Figure 8), until the sample completely melts and a single phase isotropic melt is obtained.

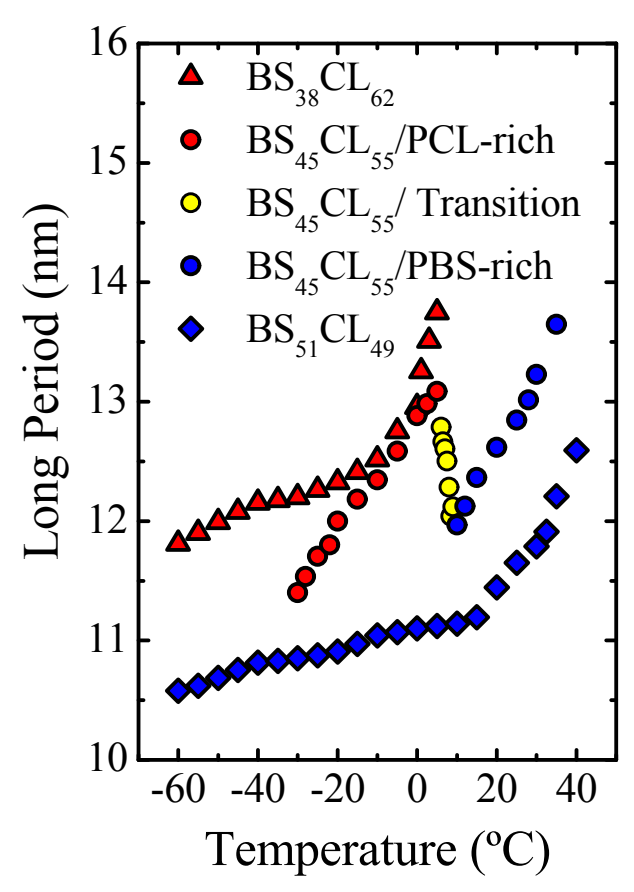

Figure 9. Long period values obtained from the SAXS maxima as a function of temperature during cooling for $\mathrm{HM}_{\mathrm{w}}$ copolyester compositions close and at the pseudo-eutectic point. 
The most interesting results are those obtained for the copolymer composition at the pseudo-eutectic point, i.e., the $\mathrm{HM}_{\mathrm{w}} \mathrm{BS}_{45} \mathrm{CL}_{55}$ copolyester sample. Figure $8 \mathrm{~b}$ should be read from bottom to top, as the sample was being heated, and it should be compared with Figure 6e (i.e., specifically with the DSC heating trace performed at $10^{\circ} \mathrm{C} / \mathrm{min}$ ).

Firstly, it is interesting to note that according to WAXS data, the PCL-rich phase is the only one whose crystallization can be detected during cooling at $10^{\circ} \mathrm{C} / \mathrm{min}$ (see WAXS patterns taken during cooling at $10^{\circ} \mathrm{C} / \mathrm{min}$ in Figure SI-7a), since the low temperature WAXS traces only show reflections that correspond to PCL (see the selected temperatures of $-50,-25,-18$, 10 and $0{ }^{\circ} \mathrm{C}$ in Figure $8 \mathrm{~b}$ ). The DSC cooling curve, on the other hand, in Figure $6 \mathrm{~b}$ shows a bimodal exotherm, that we interpret as arising from the crystallization of the PBS-rich component first (at higher temperatures) and then of the PCL component, at lower temperatures. However, the WAXS data shows that if such crystallization from the PBS phase occurs, it cannot be detected by WAXS. This is probably due to the lateral size of the crystals, which are too small for WAXS detection. However, PLOM results shown in Figure 7b, also evidenced the presence of a very small population of spherulites at $-5^{\circ} \mathrm{C}$, suggesting that a small amount of PBS-rich crystals are indeed formed during cooling from the melt, in accordance with the DSC data presented in Figure 6b.

The DSC heating scan in Figure 6e does show the melting of both phases during heating, but there is a strong cold crystallization exotherm located in the range -10 to $0{ }^{\circ} \mathrm{C}$, where WAXS evidences the crystallization of the PCL-rich crystalline phase (Figure 8b). In fact, at temperatures of $-50^{\circ} \mathrm{C}$, the WAXS trace in Figure $8 \mathrm{~b}$ indicates a very low degree of crystallinity for the PCL-rich phase (as judged by the area under the crystalline reflections). Such degree of 
crystallinity increases upon heating in a consistent way as the PCL-rich phase undergoes cold crystallization.

The PBS-rich phase only starts to crystallize during heating at $10^{\circ} \mathrm{C}$, a temperature at which, according to DSC data (Figure 6e), PCL is in the process of melting. WAXS also shows a strong decrease in the PCL (110) reflection at $10{ }^{\circ} \mathrm{C}$ (Figure 8b). Therefore, a comparison between DSC and WAXS indicates that there is an overlap between the melting of the PCLrich phase and the cold crystallization of the PBS-rich phase.

Figure 8e shows the SAXS patterns as a function of temperature during heating of the $\mathrm{BS}_{45} \mathrm{CL}_{55}$ sample at $10^{\circ} \mathrm{C} / \mathrm{min}$. Even though a single SAXS peak can be observed for all temperatures, the trend in peak position and widths of the curves changes with temperature. The biggest change occurs above $0{ }^{\circ} \mathrm{C}$, when the PCL-rich crystals start to melt and new PBS-rich crystals are formed by a cold-crystallization process.

Figure 9 plots the long periods obtained from the SAXS maxima as a function of temperature for the three samples examined. The increase in long periods with temperature is a common trend observed in semi-crystalline materials, as lamellar crystals tend to reorganize by thickening during heating (at temperatures below their melting points). At temperatures where partial melting occurs, the long period increases, typically more rapidly, as the average distance between lamellae increases as the fraction of molten polymer increases.

The sample whose composition is at the pseudo-eutectic point shows in Figure 9 a clear transition region, where the long period briefly decreases with temperature, exactly at the temperature region where PCL-rich crystals melt and PBS-rich crystals form. At temperatures below the transition, the long period is dominated by the PCL-rich lamellar crystals and above 
the transition by the PBS-rich lamellar crystals, as the comparison with the other two copolyester samples clearly suggests. The results are consistent with WAXS, DSC and PLOM results.

\section{Conclusions}

The $\mathrm{HM}_{\mathrm{w}}$ synthesized copolymers are also isodimorphic, as our previously prepared analogous $\mathrm{LM}_{\mathrm{w}}$ copolyesters. Nevertheless, the effect of molecular weight is very interesting. We found that $T_{c}$ and $T_{m}$ values, as well as lamellar thickness values, are insensitive to large molecular weight variations as they are determined by the average lengths of the crystallizable sequences which in turn are a function of the randomness of the comonomer sequence distribution and hence their selection during crystallization. However, both the crystallinity degree (as well as the long period values which depend on it) and the $T_{g}$ of the copolymers did vary significantly with increases in molecular weight, as their values depend on the entire chain length and chain mobility. Therefore, changing the molecular weight of the copolymer affords separate control over $T_{g}$ and $T_{m}$ depending on composition.

The copolymers display spherulitic superstructures whose nucleation depends on copolymer composition. At the pseudo-eutectic point, $\mathrm{HM}_{\mathrm{w}} \mathrm{BS}_{45} \mathrm{CL}_{55}$ copolyester was the only double crystalline copolymer, whose PBS-rich phase forms space filling spherulites at higher temperatures that template the superstructural morphology of the copolymer. These PBS-rich phase spherulites contain radial lamellar stacks. After cooling down to lower temperatures, the PCL-rich phase crystallizes in the interlamellar (intraspherulitic) amorphous regions with newly formed lamellae. 
Comonomer exclusion limits the average length of the crystallizable sequences and therefore $l_{c}$ decreases when comonomer addition increases at each side of the pseudo-eutectic region. Comonomer exclusion also limits the amount of crystals that can be formed and the degree of crystallinity also decreases with comonomer content while $l_{a}$ increases at each side of the pseudo-eutectic region.

In the specific cases of the $\mathrm{HM}_{\mathrm{w}} \mathrm{BS}_{45} \mathrm{CL}_{55}, \mathrm{LM}_{\mathrm{w}} \mathrm{BS}_{54} \mathrm{CL}_{46}, \mathrm{LM}_{\mathrm{w}} \mathrm{BS}_{48} \mathrm{CL}_{52}$ and $\mathrm{LM}_{\mathrm{w}}$ $\mathrm{BS}_{45} \mathrm{CL}_{55}$ copolyesters (whose compositions correspond to the pseudo-eutectic point or region), our results indicate that the cooling rate can determine which phase can crystallize and also if a single phase or two phases are formed. Very low cooling rates (below $5^{\circ} \mathrm{C} / \mathrm{min}$ ) lead to the formation of only PBS-rich crystals in $\mathrm{HM}_{\mathrm{w}}$, although for $\mathrm{LM}_{\mathrm{w}}$ both PBS-rich and PCL-rich phases can crystallize. Intermediate cooling rates allow the formation of double crystalline spherulites composed by PBS-rich and PCL-rich lamellae in both $\mathrm{HM}_{\mathrm{w}}$ and $\mathrm{LM}_{\mathrm{w}}$ copolyesters. Finally, for both $\mathrm{HM}_{\mathrm{w}}$ and $\mathrm{LM}_{\mathrm{w}}$ copolyesters when heating rates are as high as $20^{\circ} \mathrm{C} / \mathrm{min}$, only PCL-rich crystals can form. In this way, the morphology and thermal transitions of this copolyester at the pseudo-eutectic composition can be tailored for specific applications.

\section{Acknowledgments}

M.S. gratefully acknowledges the award of a PhD fellowship by POLYMAT Basque Center for Macromolecular Design and Engineering. The POLYMAT/UPV/EHU and UPC teams would like to acknowledge funding from MINECO through projects MAT2017-83014-C2-1-P and MAT-2016-77345-CO3-02 respectively, and from ALBA synchrotron facility through granted proposal 2017082318 (March 2018). 


\section{Supporting Information}

Complementary NMR characterization data (Figures SI-1 and SI-2), DSC Data (Figures SI-3 and SI-4), Polarized light Optical Micrographs (Figure SI-5) and effect of cooling rates on thermal properties (Figure SI-6) and WAXS (Figure SI-7), and WAXS data as a function of copolymer composition (SI-8). Tables SI-1-SI-5 report GPC, NMR, calorimetric and X-ray diffraction data.

\section{References}

1. Pérez-Camargo, R. A.; Arandia, I.; Safari, M.; Cavallo, D.; Lotti, N.; Soccio, M.; Müller, A. J. Crystallization of isodimorphic aliphatic random copolyesters: Pseudo-eutectic behavior and doublecrystalline materials. European Polymer Journal 2018, 101, 233-247, DOI: 10.1016/j.eurpolymj.2018.02.037.

2. Natta, G.; Corradini, P.; Sianesi, D.; Morero, D. Isomorphism phenomena in macromolecules. Journal of Polymer Science 1961, 51 (156), 527-539, DOI: 10.1002/pol.1961.1205115610

3. Allegra, G.; Bassi, I., Isomorphism in synthetic macromolecular systems. In Fortschritte der Hochpolymeren-Forschung, Springer: Berlin, 1969; pp 549-574.

4. $\quad \mathrm{Yu}, \mathrm{Y}$.; Sang, L.; Wei, Z.; Leng, X.; Li, Y. Unique isodimorphism and isomorphism behaviors of even-odd poly (hexamethylene dicarboxylate) aliphatic copolyesters. Polymer 2017, 115, 106-117, DOI: $10.1016 /$ j.polymer.2017.03.034.

5. Latere Dwan'Isa, J.-P.; Lecomte, P.; Dubois, P.; Jérôme, R. Synthesis and characterization of random copolyesters of $\varepsilon$-caprolactone and 2-oxepane-1, 5-dione. Macromolecules 2003, 36 (8), 26092615, DOI: 10.1021/ma025973t.

6. Ye, H.-M.; Wang, R.-D.; Liu, J.; Xu, J.; Guo, B.-H. Isomorphism in poly (butylene succinateco-butylene fumarate) and its application as polymeric nucleating agent for poly (butylene succinate). Macromolecules 2012, 45 (14), 5667-5675, DOI: 10.1021/ma300685f.

7. Ceccorulli, G.; Scandola, M.; Kumar, A.; Kalra, B.; Gross, R. A. Cocrystallization of random copolymers of $\omega$-pentadecalactone and $\varepsilon$-caprolactone synthesized by lipase catalysis.

Biomacromolecules 2005, 6 (2), 902-907, DOI: 10.1021/bm0493279.

8. $\quad$ Yu, Y.; Wei, Z.; Liu, Y.; Hua, Z.; Leng, X.; Li, Y. Effect of chain length of comonomeric diols on competition and miscibility of isodimorphism: A comparative study of poly (butylene glutarate-co-butylene azelate) and poly (octylene glutarate-co-octylene azelate). European Polymer Journal 2018, 105, 274-285, DOI: 10.1016/j.eurpolymj.2018.06.006.

9. Siracusa, V.; Gazzano, M.; Finelli, L.; Lotti, N.; Munari, A. Cocrystallization phenomena in novel poly (diethylene terephthalate-co-thiodiethylene terephthalate) copolyesters. Journal of Polymer Science Part B: Polymer Physics 2006, 44 (11), 1562-1571, DOI: 10.1002/polb.20819 
10. Morales-Huerta, J. C.; Martinez de Ilarduya, A.; Muñoz-Guerra, S. n. Sustainable aromatic copolyesters via ring opening polymerization: poly (butylene 2, 5-furandicarboxylate-co-terephthalate) s. ACS Sustainable Chemistry \& Engineering 2016, 4 (9), 4965-4973, DOI: 10.1021/acssuschemeng.6b01302.

11. Li, X.; Hong, Z.; Sun, J.; Geng, Y.; Huang, Y.; An, H.; Ma, Z.; Zhao, B.; Shao, C.; Fang, Y. Identifying the phase behavior of biodegradable poly (hexamethylene succinate-co-hexamethylene adipate) copolymers with FTIR. The Journal of Physical Chemistry B 2009, 113 (9), 2695-2704, DOI: $10.1021 / j p 8061866$.

12. Hong, M.; Tang, X.; Newell, B. S.; Chen, E. Y.-X. "Nonstrained" $\gamma$-Butyrolactone-Based Copolyesters: Copolymerization Characteristics and Composition-Dependent (Thermal, Eutectic, Cocrystallization, and Degradation) Properties. Macromolecules 2017, 50 (21), 8469-8479, DOI: 10.1021/acs.macromol.7b02174.

13. Yu, Y.; Wei, Z.; Zhou, C.; Zheng, L.; Leng, X.; Li, Y. Miscibility and competition of cocrystallization behavior of poly (hexamethylene dicarboxylate) s aliphatic copolyesters: effect of chain length of aliphatic diacids. European Polymer Journal 2017, 92, 71-85, DOI:

10.1016/j.eurpolymj.2017.04.036.

14. Liang, Z.; Pan, P.; Zhu, B.; Dong, T.; Hua, L.; Inoue, Y. Crystalline phase of isomorphic poly (hexamethylene sebacate-co-hexamethylene adipate) copolyester: Effects of comonomer composition and crystallization temperature. Macromolecules 2010, 43 (6), 2925-2932, DOI: 10.1021/ma1000546.

15. Papageorgiou, G. Z.; Bikiaris, D. N. Synthesis and Properties of Novel Biodegradable/Biocompatible Poly [propylene-co-(ethylene succinate)] Random Copolyesters. Macromolecular Chemistry and Physics 2009, 210 (17), 1408-1421, DOI: 10.1002/macp.200900132.

16. Pérez-Camargo, R. A.; Fernández-d'Arlas, B.; Cavallo, D.; Debuissy, T.; Pollet, E.; Avérous, L.; Müller, A. J. Tailoring the structure, morphology, and crystallization of isodimorphic poly (butylene succinate-ran-butylene adipate) random copolymers by changing composition and thermal history. Macromolecules 2017, 50 (2), 597-608, DOI: 10.1021/acs.macromol.6b02457.

17. Debuissy, T.; Sangwan, P.; Pollet, E.; Avérous, L. Study on the structure-properties relationship of biodegradable and biobased aliphatic copolyesters based on 1, 3-propanediol, 1, 4butanediol, succinic and adipic acids. Polymer 2017, 122, 105-116, DOI:

10.1016/j.polymer.2017.06.045.

18. Wang, K.; Jia, Y.-G.; Zhu, X. Two-Way Reversible Shape Memory Polymers Made of CrossLinked Cocrystallizable Random Copolymers with Tunable Actuation Temperatures. Macromolecules 2017, 50 (21), 8570-8579, DOI: 10.1021/acs.macromol.7b01815.

19. Soccio, M.; Finelli, L.; Lotti, N.; Gazzano, M.; Munari, A. Poly (propylene isophthalate), poly (propylene succinate), and their random copolymers: synthesis and thermal properties. Journal of Polymer Science Part B: Polymer Physics 2007, 45 (3), 310-321, DOI: 10.1002/polb.21049

20. Soccio, M.; Finelli, L.; Lotti, N.; Gazzano, M.; Munari, A. Novel random poly (propylene isophthalate/adipate) copolyesters: Synthesis and characterization. European polymer journal 2006, 42 (11), 2949-2958, DOI: 10.1016/j.eurpolymj.2006.07.016. 
21. Lendlein, A.; Sisson, A., Handbook of biodegradable polymers: isolation, synthesis, characterization and applications. John Wiley \& Sons: Weinheim, 2011.

22. Bechthold, I.; Bretz, K.; Kabasci, S.; Kopitzky, R.; Springer, A. Succinic acid: a new platform chemical for biobased polymers from renewable resources. Chemical Engineering \& Technology 2008, 31 (5), 647-654, DOI: 10.1002/ceat.200800063.

23. Zheng, L.; Li, C.; Wang, Z.; Wang, J.; Xiao, Y.; Zhang, D.; Guan, G. Novel biodegradable and double crystalline multiblock copolymers comprising of poly (butylene succinate) and poly ( $\varepsilon-$ caprolactone): synthesis, characterization, and properties. Industrial \& Engineering Chemistry Research 2012, 51 (21), 7264-7272, DOI: 10.1021/ie300576z.

24. Qiu, Z.; Komura, M.; Ikehara, T.; Nishi, T. Miscibility and crystallization behavior of biodegradable blends of two aliphatic polyesters. Poly (butylene succinate) and poly ( $\varepsilon$-caprolactone). Polymer 2003, 44 (25), 7749-7756, DOI: 10.1016/j.polymer.2003.10.013.

25. Alamo, R. G.; Viers, B. D.; Mandelkern, L. Phase structure of random ethylene copolymers: a study of counit content and molecular weight as independent variables. Macromolecules 1993, 26 (21), 5740-5747, DOI: 10.1021/ma00073a031.

26. Di Lorenzo, M.; Silvestre, C. Non-isothermal crystallization of polymers. Progress in Polymer Science 1999, 24 (6), 917-950, DOI: 10.1016/S0079-6700(99)00019-2.

27. Ciulik, C.; Safari, M.; Martínez de Ilarduya, A.; Morales-Huerta, J. C.; Iturrospe, A.; Arbe, A.; Müller, A. J.; Muñoz-Guerra, S. Poly (butylene succinate-ran- $\varepsilon$-caprolactone) copolyesters: Enzymatic synthesis and crystalline isodimorphic character. European Polymer Journal 2017, 95, 795-808, DOI: 10.1016/j.eurpolymj.2017.05.002.

28. Cao, A.; Okamura, T.; Ishiguro, C.; Nakayama, K.; Inoue, Y.; Masuda, T. Studies on syntheses and physical characterization of biodegradable aliphatic poly (butylene succinate-co- $\varepsilon$ caprolactone) s. Polymer 2002, 43 (3), 671-679, 10.1016/S0032-3861(01)00658-9.

29. Arandia, I.; Mugica, A.; Zubitur, M.; Arbe, A.; Liu, G.; Wang, D.; Mincheva, R.; Dubois, P.; Müller, A. J. How composition determines the properties of isodimorphic poly (butylene succinateran-butylene azelate) random biobased copolymers: from single to double crystalline random copolymers. Macromolecules 2014, 48 (1), 43-57, DOI: 10.1021/ma5023567.

30. Castillo, R.; Müller, A. Crystallization and morphology of biodegradable or biostable single and double crystalline block copolymers. Progress in Polymer Science 2009, 34 (6), 516-560, DOI: 10.1016/j.progpolymsci.2009.03.002.

31. Palacios, J. K.; Mugica, A.; Zubitur, M.; Müller, A. J., Crystallization and Morphology of Block Copolymers and Terpolymers With More Than One Crystallizable Block. In Crystallization in Multiphase Polymer Systems, Elsevier: 2018; pp 123-180, DOI: 10.1016/B978-0-12-809453-2.000062.

32. Mandelkern, L., Crystallization of polymers. 2nd edition ed.; Cambridge University Press: Cambridge 2002; Vol. 1, Equilibrium Concepts, DOI: 10.1017/CBO9780511535413.001.

33. Van Krevelen, D. W.; Te Nijenhuis, K., Properties of polymers: their correlation with chemical structure; their numerical estimation and prediction from additive group contributions. Elsevier: Amsterdam, 2009. 
34. Pitt, C. G.; Chasalow, F.; Hibionada, Y.; Klimas, D.; Schindler, A. Aliphatic polyesters. I. The degradation of poly (€-caprolactone) in vivo. Journal of Applied Polymer Science 1981, 26 (11), 37793787, DOI: 10.1002/app.1981.070261124.

35. Hiemenz, P. C.; Lodge, T. P., Polymer chemistry. CRC press: Boca Raton, 2007.

36. Schneider, H.; Rieger, J.; Penzel, E. The glass transition temperature of random copolymers: 2. Extension of the Gordon-Taylor equation for asymmetric Tg vs composition curves. Polymer 1997, 38 (6), 1323-1337, DOI: 10.1016/S0032-3861(96)00652-0.

37. Simha, R.; Boyer, R. On a general relation involving the glass temperature and coefficients of expansion of polymers. The Journal of Chemical Physics 1962, 37 (5), 1003-1007, DOI: $10.1063 / 1.1733201$.

38. Pinal, R. Entropy of mixing and the glass transition of amorphous mixtures. Entropy 2008, 10 (3), 207-223, DOI:10.3390/entropy-e10030207.

39. Penzel, E.; Rieger, J.; Schneider, H. The glass transition temperature of random copolymers: 1. Experimental data and the Gordon-Taylor equation. Polymer 1997, 38 (2), 325-337, DOI: 10.1016/S0032-3861(96)00521-6.

40. Díaz, A.; Franco, L.; Puiggalí, J. Study on the crystallization of poly (butylene azelate-cobutylene succinate) copolymers. Thermochimica Acta 2014, 575, 45-54, DOI:

10.1016/j.tca.2013.10.013. 
For table of contents use only

Tuning the thermal properties and morphology of isodimorphic poly[(butylene succinate)-ran-(E-caprolactone)] copolyesters by changing composition, molecular weight and thermal history

\author{
Maryam Safari ${ }^{1}$, Antxon Martínez de Ilarduya ${ }^{2}$, Agurtzane Mugica $^{1}$, Manuela Zubitur ${ }^{3}$, \\ Sebastián Muñoz-Guerra², Alejandro J. Müller*1,4
}

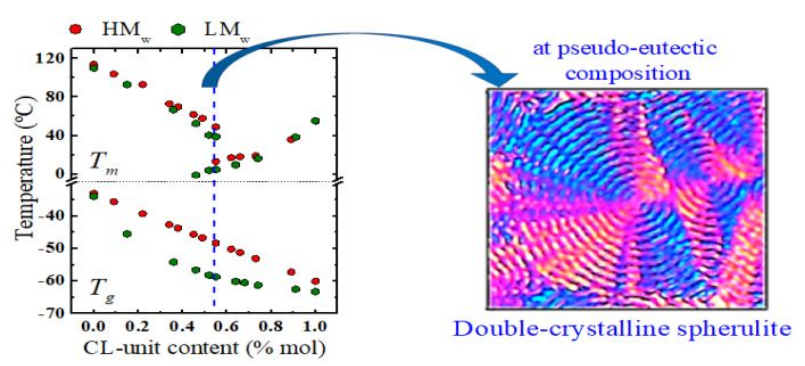

